\title{
Elasticity and lattice dynamics of enstatite at high pressure
}

\author{
Dongzhou Zhang, ${ }^{1}$ Jennifer M. Jackson, ${ }^{1}$ Bin Chen, ${ }^{1,2}$ Wolfgang Sturhahn, ${ }^{1}$ \\ Jiyong Zhao, ${ }^{3}$ Jinyuan Yan, ${ }^{4}$ and Razvan Caracas ${ }^{5}$ \\ Received 18 February 2013; revised 16 July 2013; accepted 22 July 2013; published 27 August 2013.
}

[1] The behavior of synthetic-powdered ${ }^{57} \mathrm{Fe}$-enriched enstatite $\left(\mathrm{Mg}_{0.980} \mathrm{Fe}_{0.020(5)}\right)\left(\mathrm{Mg}_{0.760} \mathrm{Fe}_{0.240}\right) \mathrm{Si}_{2} \mathrm{O}_{6}$ has been explored by X-ray diffraction (XRD) and nuclear resonant inelastic X-ray scattering (NRIXS). The Pbca-structured enstatite sample was compressed in fine pressure increments for our independent XRD measurements. One structural transition between 10.1 and $12.2 \mathrm{GPa}$ has been identified from the XRD data. The XRD reflections observed for the high-pressure phase are best matched with space group $P 2{ }_{1} / c$. We combine density functional theory with Mössbauer spectroscopy and NRIXS to understand the local site symmetry of the Fe atoms in our sample. A third-order Birch-Murnaghan (BM3) equation of state fitting gives $K_{T 0}=103 \pm 5 \mathrm{GPa}$ and $K_{T 0}^{\prime}=13 \pm 2$ for the $P b c a$ phase. At $12 \mathrm{GPa}$, a BM3 fitting gives $K_{T 12}=220 \pm 10 \mathrm{GPa}$ with $K_{T 12}^{\prime}=8 \pm 4$ for the $P 2_{1} / c$ phase. NRIXS measurements were performed with in situ XRD up to $17 \mathrm{GPa}$. The partial phonon density of states (DOS) was derived from the raw NRIXS data, and from the low-energy region of the DOS, the Debye sound velocity was determined. We use the equation of state determined from XRD and Debye sound velocity to compute the isotropic compressional $\left(V_{P}\right)$ and shear $\left(V_{S}\right)$ wave velocities of enstatite at different pressures. Our results help constrain the high-pressure properties of $P b c a$-structured enstatite in the Earth's upper mantle. We find that candidate upper mantle phase assemblages containing $\mathrm{Pbca}$-structured enstatite are associated with shear velocity gradients that are higher than the average Earth model PREM but lower than regional studies down to about $250 \mathrm{~km}$ depth.

Citation: Zhang, D., J. M. Jackson, B. Chen, W. Sturhahn, J. Zhao, J. Yan, and R. Caracas (2013), Elasticity and lattice dynamics of enstatite at high pressure, J. Geophys. Res. Solid Earth, 118, 4071-4082, doi:10.1002/jgrb.50303.

\section{Introduction}

[2] The upper mantle plays an important role in the Earth's interior, as the interplay between this region and the lithosphere helps drive plate tectonics, which shapes the surface of the Earth. The depth region between 250 and $300 \mathrm{~km}$ is of specific interest in this study. In this depth range, two general features from seismic observations have been identified. One feature is the horizontal variation in $S$ wave velocities from different seismic models. These models include global average 1-D models (PREM [Dziewonski and

\footnotetext{
${ }^{1}$ Seismological Laboratory, Division of Geological and Planetary Sciences, California Institute of Technology, Pasadena, California, USA.

${ }^{2}$ Now at COMPRES Technology Center, Argonne, Illinois, USA.

${ }^{3}$ Advanced Photon Source, Argonne National Laboratory, Argonne, Illinois, USA.

${ }^{4}$ Advanced Light Source, Lawrence Berkeley National Laboratory, Berkeley, California, USA.

${ }^{5}$ Centre National de la Recherche Scientifique, Université de Lyon, Université Claude Bernard Lyon 1, Ecole Normale Supérieure de Lyon, Lyon, France.

Corresponding author: D. Zhang, Seismological Laboratory, Division of Geological and Planetary Sciences, California Institute of Technology, 1200 E. California Blvd., Pasadena, CA 91125, USA. (dzzhang@caltech.edu)

(C)2013. American Geophysical Union. All Rights Reserved. 2169-9313/13/10.1002/jgrb.50303
}

Anderson, 1981] and AK135 [Kennett et al., 1995]) and regional models for the western United States (TNA [Grand and Helmberger, 1984a]), the eastern North American continent (SNA [Grand and Helmberger, 1984a]), the North Atlantic Ocean (ATL [Grand and Helmberger, 1984b]), and the Pacific Ocean (PAC06 [Tan and Helmberger, 2007]). However, little horizontal variation in the $P$ wave velocity structure for this depth range has been reported among different models, including the comparison among global average 1-D models (PREM and AK135) and regional models for the tectonically active western United States (mT7 [Chu et al., 2011]) and the tectonically stable eastern North American continent (CR [Chu et al., 2012] and S25 [LeFevre and Helmberger, 1989]). These seismological models serve as important constraints on determining the composition of this region, because the elasticity of stable phase assemblages must be consistent with seismic observations. The other feature of interest in this depth range is the seismic $\mathrm{X}$ discontinuity, which is a group of seismic reflections located between 240 and $340 \mathrm{~km}$ in depth associated with a shear impedance increase of 3-7.5\% [Deuss and Woodhouse, 2002; Revenaugh and Jordan, 1991]. The X discontinuity is widespread, but not global, and is characterized by a large depth variation [Deuss and Woodhouse, 2002; Revenaugh and Jordan, 1991]. The presence of hydrated phases in the 
upper mantle has been invoked to explain the $\mathrm{X}$ discontinuity [Revenaugh and Jordan, 1991; Jacobsen et al., 2010]. However, the $\mathrm{X}$ discontinuity has been reported in regions corresponding to the underside of subducted slabs, where hydrated phases are unlikely to be present [Woodland and Angel, 1997; Woodland, 1998].

[3] $(\mathrm{Mg}, \mathrm{Fe})_{2} \mathrm{Si}_{2} \mathrm{O}_{6}$ enstatite is the second most abundant mineral in peridotite [Ringwood, 1991; Frost, 2008], containing about 10 to $15 \% \mathrm{Fe}_{2} \mathrm{Si}_{2} \mathrm{O}_{6}$, and is one of the three most abundant components in compositional models of the deep upper mantle [Bass and Anderson, 1984; Irifune and Ringwood, 1987; Ringwood, 1991]. The elasticity of orthoenstatite (OEN) has been used to construct petrological models and compare to mantle seismic velocity structures [e.g., Bass and Anderson, 1984; Duffy and Anderson, 1989], and the orthoenstatite (OEN, space group $\mathrm{Pbca}$ ) to high-pressure clinoenstatite (HP-CEN, space group $C 2 / c$ ) transition has been suggested to explain the $\mathrm{X}$ discontinuity for several reasons. The OEN to HP-CEN transition has a suitable $\mathrm{P}-\mathrm{T}$ range for the $\mathrm{X}$ discontinuity ( 8.5-9.5 GPa along a $1400^{\circ} \mathrm{C}$ adiabat) [Woodland and Angel, 1997; Woodland, 1998; Kung et al., 2005; Akashi et al., 2009]. Enstatite's abundance in proposed compositional models can explain the existence of $\mathrm{X}$ discontinuity in the underside region of subducted slabs [Woodland and Angel, 1997; Woodland, 1998]. The OEN to HP-CEN/majorite-garnet multivariant transition occurs over a large depth interval and is unlikely to produce a sharp seismic discontinuity, thus potentially explaining the wide variability of the $\mathrm{X}$ discontinuity [Woodland and Angel, 1997; Woodland, 1998]. Further, recent studies on the pressure-induced transitions of OEN have provided new information regarding the high-pressure symmetry of enstatite [Zhang et al., 2011; Jahn, 2008; Zhang et al., 2012]. Though multianvil experiments have shown that $\mathrm{Mg}_{2} \mathrm{Si}_{2} \mathrm{O}_{6}$ HP-CEN phase is the stable phase at $14 \mathrm{GPa}$ and $1000^{\circ} \mathrm{C}$ [Kung et al., 2004], a high-pressure study on the vibrational properties of iron-bearing enstatite is still lacking. A better understanding of the high-pressure elastic properties of enstatite with a composition similar to that inferred from petrological observations is needed to make more conclusive statements linking upper mantle seismic structures with the presence of enstatite.

[4] In this study, we present measurements of the elastic properties and lattice dynamics of $(\mathrm{Mg}, \mathrm{Fe})_{2} \mathrm{Si}_{2} \mathrm{O}_{6}$ enstatite using X-ray diffraction (XRD) and nuclear resonant inelastic X-ray scattering (NRIXS). XRD has been used in the past to determine the crystal structure, unit cell volume, and $\mathrm{P}-\mathrm{V}$ equation of state of enstatite [e.g., Hugh-Jones and Angel, 1994; Angel and Jackson, 2002; Akashi et al., 2009]. NRIXS provides information concerning the lattice dynamics of a phase [Sturhahn, 2004] and has also been applied to OEN at ambient conditions [Jackson et al., 2009]. Therefore, in comparison with experimental techniques that have also been used to probe the sound velocities of enstatite, such as Brillouin spectroscopy [e.g., Weidner et al., 1978; Duffy and Vaughan, 1988; Jackson et al., 1999, 2004], ultrasonic interferometry [Frisillo and Barsch, 1972; Webb and Jackson, 1993; Flesch et al., 1998; Kung et al., 2004], and impulsive stimulated light scattering [Chai et al., 1997], NRIXS provides additional information via the partial projected phonon density of states (DOS), such as the mean square displacement of the iron atoms and the average force constant of the iron sublattice [Sturhahn, 2004; Jackson et al., 2009]. Further, we supplement our experimental results from NRIXS with first-principles calculations to understand how the local site symmetry of the iron atoms may affect the DOS of enstatite. Finally, we combine the elastic properties of iron-bearing enstatite determined in this study with past experimental reports on candidate phases to construct shear velocity profiles of likely petrologies in the Earth's upper mantle. We compare these profiles to global and regional seismic studies, as well as to characteristics of the $\mathrm{X}$ discontinuity.

\section{Methodology}

[5] Powdered starting materials of OEN-structured $\left(\mathrm{Mg},{ }^{57} \mathrm{Fe}\right){ }_{2} \mathrm{Si}_{2} \mathrm{O}_{6}$ with $13 \mathrm{~mol} \%{ }^{57} \mathrm{Fe}_{2} \mathrm{Si}_{2} \mathrm{O}_{6}$ (hereafter referred to as En87) were prepared for high-pressure NRIXS experiments. The starting ${ }^{57} \mathrm{Fe}_{2} \mathrm{Si}_{2} \mathrm{O}_{6}$ was $95 \%$ ${ }^{57} \mathrm{Fe}$ enriched. The samples in this experiment were taken from the same run charge that was used in a nuclear resonant scattering study at ambient conditions [Jackson et al., 2009] and high pressures [Zhang et al., 2011], where the distribution of Fe in the M1 and M2 sites was determined by synchrotron Mössbauer spectroscopy giving the formula $\left(\mathrm{Mg}_{0.980} \mathrm{Fe}_{0.020(5)}\right)\left(\mathrm{Mg}_{0.760} \mathrm{Fe}_{0.240}\right) \mathrm{Si}_{2} \mathrm{O}_{6}$ [Zhang et al., 2011]. Two individual diamond anvil cells (DACs) were loaded with En87 for high-pressure XRD and NRIXS measurements. We describe the DAC preparations, experimental details, and first-principles calculations below.

\subsection{X-Ray Diffraction}

[6] For the XRD measurements, one symmetric DAC was used. Two type-I diamonds with culets $300 \mu \mathrm{m}$ in diameter were mounted and aligned to form the anvils. A Re gasket was preindented to $\sim 50 \mu \mathrm{m}$ thick, and a $125 \mu \mathrm{m}$ diameter hole was drilled in the center of the preindention using an electrical discharge machine. An $\sim 25 \mu \mathrm{m}$ thick sample ( $\sim 30 \mu \mathrm{m}$ in diameter) was first compacted out of the powder and then loaded into the gasket hole with two ruby spheres ( $\sim 10 \mu \mathrm{m}$ in diameter) surrounding the sample. The DAC was then Ne gas loaded [Rivers et al., 2008]. After gas loading, the diameter of the sample chamber shrank to $\sim 55 \mu \mathrm{m}$. The ruby spheres were used to determine the pressure in the sample chamber below 4.6 GPa [Mao et al., 1986], where $\mathrm{Ne}$ is in the liquid state [Shimizu et al., 2005]. We estimate the uncertainty in pressure determined using the ruby fluorescence method by computing the standard deviation of the pressure given by the different rubies in the sample chamber before and after each XRD measurement. At pressures above 4.6 GPa, Ne crystallizes and in situ Ne volumes were used to determine the pressure via the $\mathrm{Ne}$ equation of state [Dewaele et al., 2008]. As the X-ray sampled enstatite and $\mathrm{Ne}$ at the same location, using $\mathrm{Ne}$ as a pressure gauge reduced the influence of potential pressure gradients in the sample chamber [Boehler, 2000]. Based on the positions of $\mathrm{Ne}(111)$ and (200) diffraction peaks, we estimate the Ne pressure uncertainty to be 0.1 to $0.2 \mathrm{GPa}$ from 5.1 to 19.1 GPa (Table 1).

[7] The XRD measurements were carried out at beamline 12.2.2 of the Advanced Light Source (ALS) at Lawrence Berkeley National Laboratory. The energy $(30 \mathrm{keV})$ and 
Table 1. Unit Cell Volumes of the OEN Phase (Pbca) and the HP Phase $\left(P 2{ }_{1} / c\right)$ as a Function of Pressure at Room Temperature Determined From the XRD Data Refinements Using the Reflections Shown in Figure $1 \mathrm{a}^{\mathrm{a}}$

\begin{tabular}{lcccc}
\hline \multicolumn{3}{c}{ OEN } & & \multicolumn{2}{c}{ HP } \\
\cline { 1 - 2 } \cline { 5 - 5 } Pressure $(\mathrm{GPa})$ & Volume $\left(\AA^{3}\right)$ & & Pressure $(\mathrm{GPa})$ & Volume $\left(\AA^{3}\right)$ \\
\hline 0 & $836(3)$ & & $10.1(1)$ & $773(2)$ \\
$3.0(2)$ & $816(2)$ & & $10.4(1)$ & $773(2)$ \\
$3.5(2)$ & $811(2)$ & & $10.8(2)$ & $772(2)$ \\
$4.5(3)$ & $807(2)$ & & $11.2(2)$ & $770(2)$ \\
$4.6(4)$ & $806(2)$ & & $11.7(1)$ & $768(2)$ \\
$5.1(1)$ & $805(2)$ & & $12.2(1)$ & $767(2)$ \\
$5.5(1)$ & $802(2)$ & & $12.7(1)$ & $765(2)$ \\
$5.7(1)$ & $800(2)$ & & $13.2(1)$ & $762(2)$ \\
$6.2(1)$ & $799(2)$ & & $14.0(1)$ & $760(2)$ \\
$6.7(1)$ & $797(2)$ & & $14.5(1)$ & $757(2)$ \\
$7.1(1)$ & $794(2)$ & & $15.0(1)$ & $757(2)$ \\
$8.3(1)$ & $788(2)$ & & $15.6(1)$ & $755(2)$ \\
$8.6(1)$ & $788(2)$ & & $16.2(1)$ & $753(2)$ \\
$9.0(1)$ & $785(2)$ & & $16.7(2)$ & $752(2)$ \\
$9.3(1)$ & $785(2)$ & & $18.2(2)$ & $748(2)$ \\
$9.5(1)$ & $784(2)$ & & $19.1(1)$ & $746(2)$ \\
$9.9(1)$ & $783(2)$ & & - & - \\
$10.1(1)$ & $782(2)$ & & - & - \\
$10.4(1)$ & $782(2)$ & & - & - \\
$10.8(2)$ & $780(2)$ & & - & - \\
$11.2(2)$ & $779(3)$ & & - & - \\
$11.7(1)$ & $776(4)$ & & - & - \\
$12.2(1)$ & $774(3)$ & - & - \\
\hline
\end{tabular}

a Pressures were determined using the ruby fluorescence method [Mao et al., 1986] (below 4.6 GPa), and from the Ne unit cell volume using the BM3 EOS from Dewaele et al. [2008] (above 4.6 GPa). For pressure determination, $\mathrm{Ne}(111)$ and (200) peaks were used. Values in parentheses indicate the uncertainty in the last significant digit.

resolution $(1 \mathrm{eV})$ of the X-rays were determined by a high heat load monochromator, and a focus area of $10 \mu \mathrm{m} \times 20 \mu \mathrm{m}$ (full width at half maximum) was achieved by a Kirkpatrick-Baez mirror system and cleanup slits. A high-resolution mar345 Image Plate Detector System located in the downstream direction of the DAC with a distance of about $0.5 \mathrm{~m}$, was used to collect

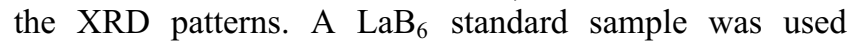
to calibrate the sample to image plate distance and correct the tilting of the image plate. The diffraction images were integrated into angular-resolved chi files using Fit2D [Hammersley et al., 1996] (Figure 1a). Diffraction peaks in the $2 \theta$ range between 7 and $12^{\circ}$ can be indexed with enstatite peaks. We used the peaks in this $2 \theta$ range to fit the unit cell volume of En87 (labeled in Figure 1a), as this range provided enough peaks for volume refinement, avoided the interference of peaks from other materials such as $\mathrm{Ne}$, and had a relatively flat background. The cleanup slits reduced, but did not eliminate, the influence of X-ray intensity in the tails of the focus area. This effect combined with Re's relatively strong atomic scattering factor [Henke et al., 1993] thus leads to some contribution of the Re gasket to the XRD patterns (Figure 1a). Diffraction peaks in the angularresolved chi files were fit to a Gaussian shape, and their central position and full width at half maximum served as the input of the unit cell volume and associated uncertainty, respectively. The unit cell volume of the sample was refined using UnitCell [Holland and Redfern, 1997]. In most cases, the volume uncertainty was estimated to be $3 \%$ of the unit cell volume, which is larger than the $2 \sigma$ errors provided by
UnitCell. To determine the best fit equations of state (EOS), the P-V data sets were analyzed using the EOS-FIT (V5.2) least squares package [Angel, 2000] (Figures 2 and 3).

\subsection{Nuclear Resonant Inelastic $X$-Ray Scattering}

[8] For the nuclear resonant inelastic X-ray scattering measurements (NRIXS), a panoramic DAC with three large radial openings separated by $120^{\circ}$ around the sample was used, so as to increase the detection area and therefore the signal. The panoramic DAC was modified with a $90^{\circ}$ opening and a cubic boron nitride backing plate on the downstream side, thus maximizing the range of available diffraction angles for in situ XRD. Similar to the DAC prepared for XRD measurements, two type-I diamonds with culets $300 \mu \mathrm{m}$ in diameter were mounted and aligned to form the anvils. A Be gasket was used to decrease X-ray absorption in the radial direction. The gasket was preindented to $\sim 50 \mu \mathrm{m}$ thick, and a $125 \mu \mathrm{m}$ diameter hole was
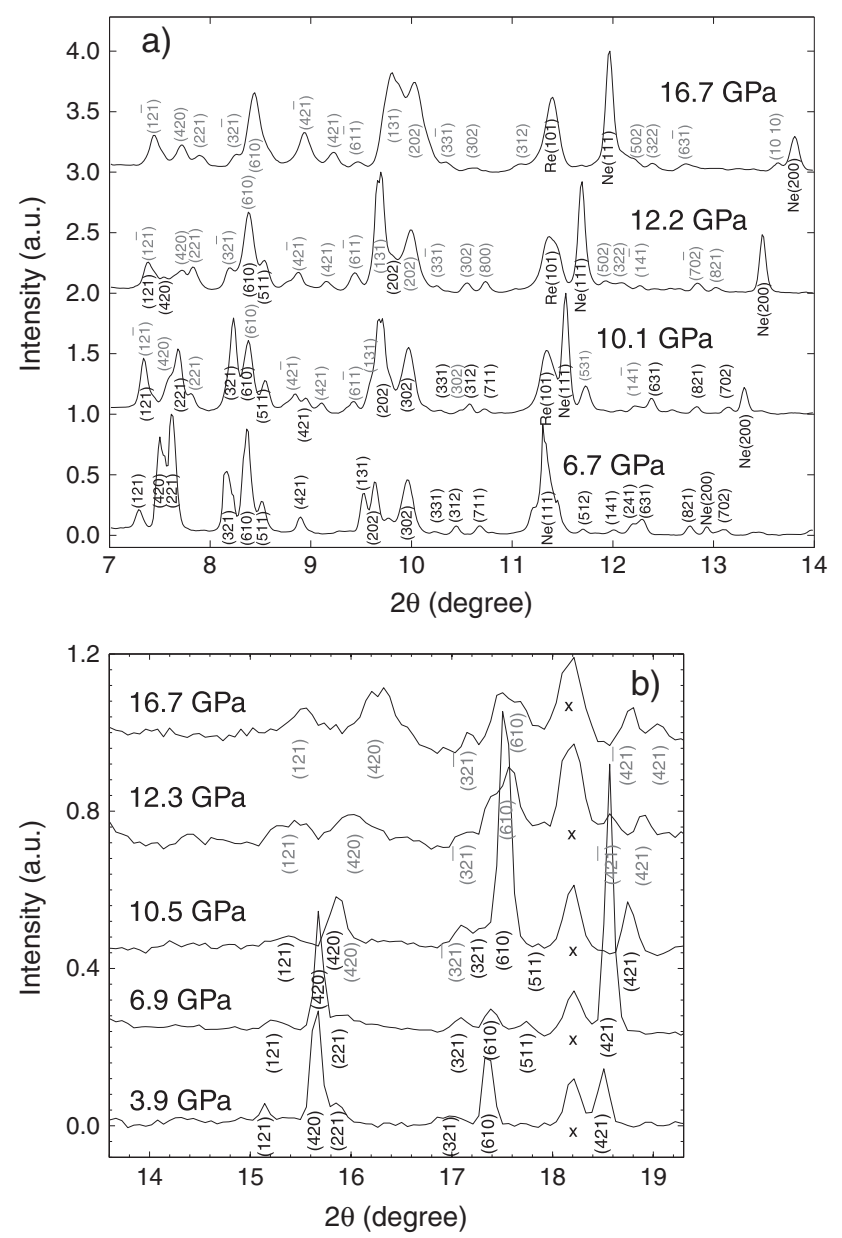

Figure 1. (a) Select XRD patterns at different pressures taken at beamline 12.2 .2 of the ALS $(\mathrm{E}=30 \mathrm{keV})$. The $h k l$ indices for the OEN phase (Pbca, black) and HP phase $\left(P 2_{1} / c\right.$, gray) are labeled near each peak. Ne and Re peaks are also labeled. (b) Select in situ XRD patterns taken at beamline 3-ID-B of the Advanced Photon Source at the ${ }^{57} \mathrm{Fe}$ nuclear resonance energy of $14.4125 \mathrm{keV}$. Ruby $\left(\mathrm{Al}_{2} \mathrm{O}_{3}\right)$ (104) peak (crosses). The background has been subtracted in each pattern. 


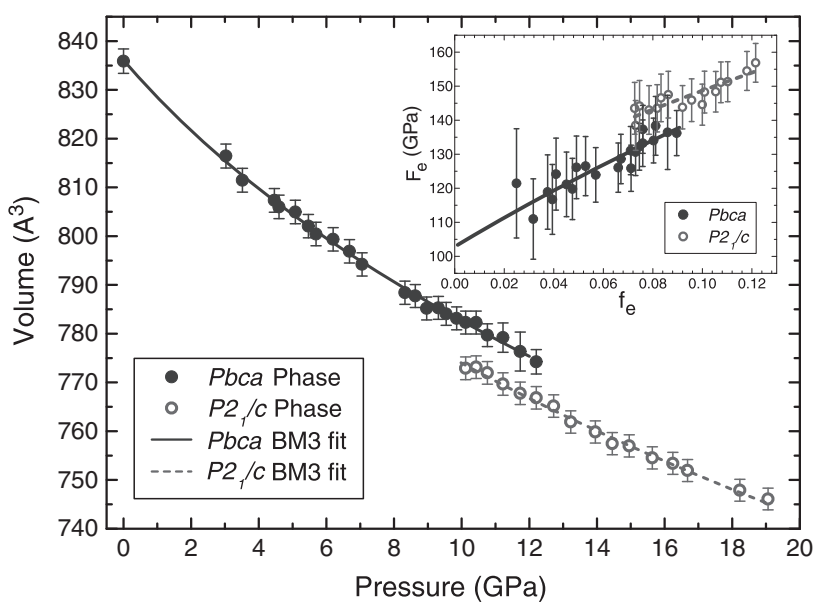

Figure 2. Unit cell volume as a function of pressure for En87 compressed using $\mathrm{Ne}$ as a pressure-transmitting medium (Table 1). The best fit third-order Birch-Murnaghan (BM3) equations of state for the two phases are shown as lines (see text for details). Normalized pressure $\left(\mathrm{F}_{e}\right)$ versus Eulerian finite strain $\left(\mathrm{f}_{e}\right)$ for the En87 sample (inset). Lines are calculated from our reported BM3 EOS.

drilled in the center of the preindention using an electrical discharge machine. The gasket hole was then filled with amorphous boron epoxy to hold the pressure and ensure that the sample maintained a relatively large thickness with increasing pressure. We mechanically drilled an $\sim 50 \mu \mathrm{m}$ diameter hole into the epoxy insert and loaded an $\sim 25 \mu \mathrm{m}$ thick sample $(\sim 30 \mu \mathrm{m}$ in diameter, compacted out of the powder) into it. Neon was loaded into the sample chamber of the DAC at the GeoSoilEnviro Center for Advanced Radiation Sources (GSECARS) at the APS [Rivers et al., 2008]. Two ruby spheres $(\sim 10 \mu \mathrm{m}$ in diameter $)$ were placed around the En87 sample to monitor the pressure in the sample chamber [Mao et al., 1986], as Ne diffraction peaks were not visible in the sampled $2 \theta$ range (Figure $1 \mathrm{~b}$ ).

[9] NRIXS experiments were performed at sector 3ID-B of the Advanced Photon Source at Argonne National Laboratory. The energy bandwidth of the incident X-rays determines the resolution of the phonon spectra. The X-rays were prepared with bandwidths of $1 \mathrm{meV}$ using a multiplecrystal Bragg reflection monochromator [Toellner, 2000]. A Kirkpatrick-Baez mirror system was used to obtain a focal spot size of $\sim 10 \times 10 \mu \mathrm{m}^{2}$ at the full width at half maximum [Zhao et al., 2004]. The storage ring was operated in low-emittance top-up mode with 24 bunches that were separated by $153 \mathrm{~ns}$. For each spectrum, the monochromator was tuned from -75 to $+90 \mathrm{meV}$ around the nuclear resonance energy of ${ }^{57} \mathrm{Fe}(14.4125 \mathrm{keV})$, with a step size of $0.25 \mathrm{meV}$ and a collection time of $5 \mathrm{~s}$ per energy step (Figure 4a). The radiation emitted from the sample was observed with four avalanche photodiode detectors. Three detectors were placed around and close to the sample ( $\sim 2 \mathrm{~mm}$ away) to collect the incoherent inelastic scattered photons, and the fourth detector was placed downstream $(\sim 100 \mathrm{~cm})$ in the forward scattering direction, in order to obtain the resolution function independently. The counting rates were low due to the small thickness (in order to achieve pressure) and low ${ }^{57} \mathrm{Fe}$ concentration. Therefore, $\sim 10$ spectra per pressure were collected, and the average total counting rate in the highest Stokes peak was $\sim 2.2 \mathrm{c} / \mathrm{s}$. In situ X-ray diffraction patterns $(\mathrm{E}=14.4125 \mathrm{keV}$ and $\lambda=0.86025 \AA)$ were collected at sector 3-ID-B before and after each NRIXS compression point to determine the unit cell volume of the enstatite sample (Figure 1b). We use these volumes to compute the pressure via the best fit BM3 EOS determined from our independent XRD measurements at the ALS (see section 3.1). We did not observe any indication of sample amorphization over the compression range investigated here. The NRIXS data were analyzed using the PHOENIX software package, and a quasi-harmonic model was used to extract the partial phonon density of states (Figure $4 \mathrm{~b}$ ) from the measured raw NRIXS spectra [Sturhahn, 2000].

\subsection{First-Principles Calculations}

[10] We employ density functional theory (DFT) [Hohenberg and Kohn, 1964; Kohn and Sham, 1965] and density functional perturbation theory [Baroni et al., 1987, 2001; Gonze and Vigneron, 1989; Gonze et al., 1992, 2005] to compute the phonon density of states of $\mathrm{Mg}_{2} \mathrm{Si}_{2} \mathrm{O}_{6}$ OEN. We employ Troullier-Martins-type pseudopotentials [Troullier and Martins, 1991] generated with the Fritz Haber Institute code [Fuchs and Scheffler, 1999], and the generalized gradient approximation in the Perdew-Burke-Ernzerhof formulation [Perdew et al., 1996]. All the calculations are static $(\mathrm{T}=0 \mathrm{~K})$, and the phonons and DOS are computed in the quasi-harmonic approximation. We fully relax the crystal structure of OEN, minimizing both the residual interatomic forces and the residual nonhydrostatic stresses. We use a $1 \times 2 \times 4$ special grid of high-symmetry $\mathbf{k}$ points [Monkhorst and Pack, 1976] and a cutoff for the plane wave kinetic energy of 34 hartrees $(1 \mathrm{Ha}=27.2116 \mathrm{eV})$. These parameters ensure an accuracy of the calculations better than $1 \mathrm{mHa}$ in energy. We compute the phonons in the Brillouin zone center at ambient pressure. The phonon density of states is built as a summation of the phonon band dispersion, which, in turn, is obtained using Fourier trans-

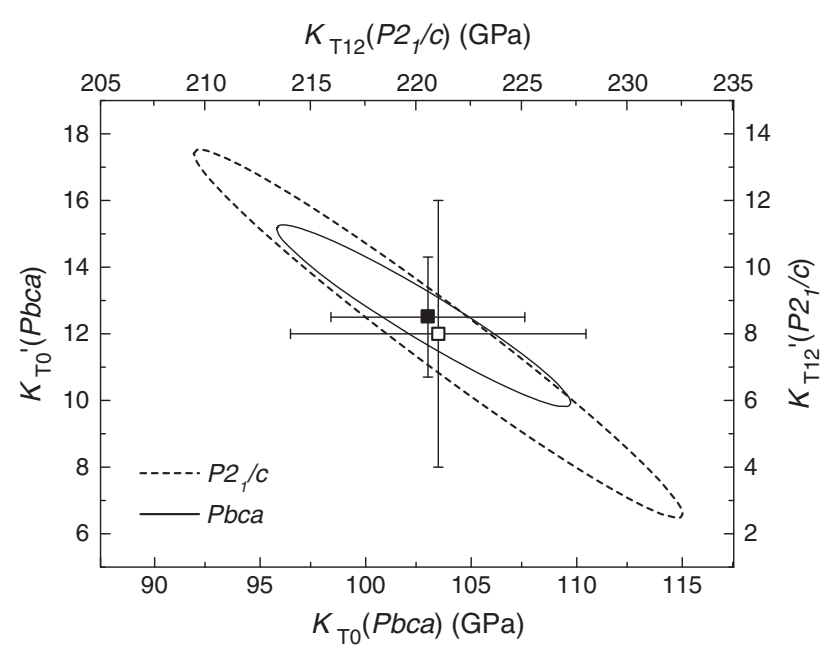

Figure 3. Confidence ellipses in $K_{T}$ and $K_{T}^{\prime}$ for the fit of the BM3 EOS to the En87 P-V data (see text). Pbca (solid square and line). $P 2_{1} / c$ (open square and dashed line). Error bars are given at levels of $1 \sigma$. The $68 \%$ confidence ellipses are calculated for 2 degrees of freedom [Angel, 2000]. 

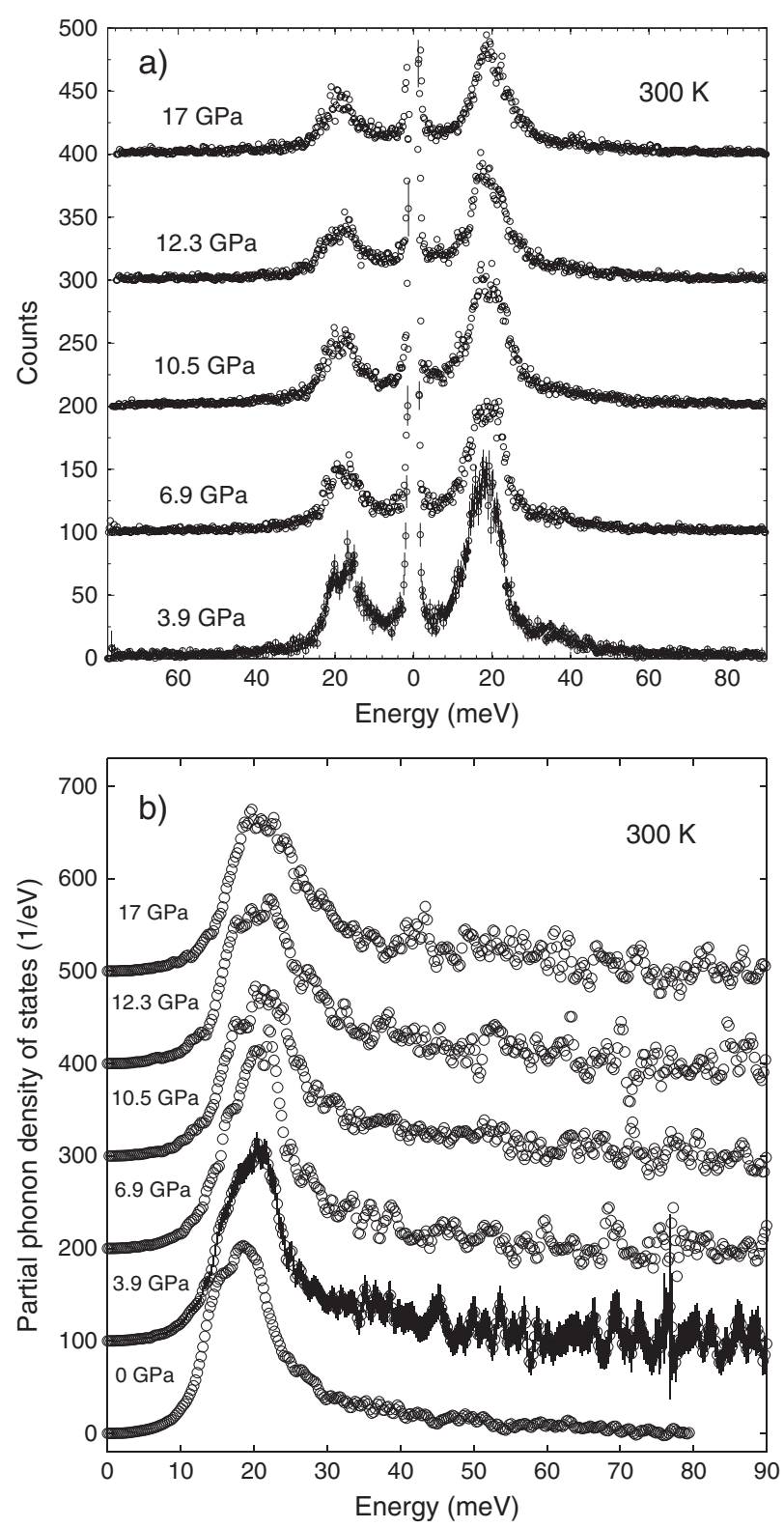

Figure 4. (a) Select NRIXS spectra of En87. Data are shifted vertically. The errors for $6.9,10.5,12.3$, and $17 \mathrm{GPa}$ are similar to the error of $3.9 \mathrm{GPa}$ but are not plotted for clarity. (b) Partial projected phonon density of states of En87 at different pressures. Each spectrum is offset by 100 units in the vertical direction. Error bars for the ambient pressure data [Jackson et al., 2009] are less than the size of the symbol. Errors for the high-pressure data are similar to those of the $3.9 \mathrm{GPa}$ data.

form techniques of the interatomic force constants matrix at Gamma [Gonze et al., 1992; Baroni et al., 2001].

[11] The DFT calculations are performed on pure $\mathrm{Mg}_{2} \mathrm{Si}_{2} \mathrm{O}_{6}$ compositions. Fe can enter the pyroxene structure on the M1 and/or M2 sites. Once the interatomic force constants matrix is computed for $\mathrm{Mg}_{2} \mathrm{Si}_{2} \mathrm{O}_{6}$, we only alter the mass of the atom on the M1 or M2 site corresponding to the desired amount of iron on that particular position. This is a standard procedure employed for studying isotope partitioning [Schauble, 2004]. We assign the altered mass to be consistent with the composition of our sample studied by NRIXS. Thus, $25 \% \mathrm{Fe}$ on either M1 or M2 site in substitution to $\mathrm{Mg}$ yields a mass of 32.190 . Using the new masses, we recompute the dynamical matrices and reconstruct the phonon density of states (Figure 5). The procedure ensures a first-order approximation of the effect of iron on the total and $\mathrm{Fe}$ partial phonon density of states. It has a relatively reduced computational cost and also presents the advantage of preserving the lattice symmetry.

\section{Results}

\subsection{X-Ray Diffraction}

[12] We use our results from XRD measurements at the ALS (section 2.1) to determine the pressure-volume equation of state and to monitor the change of crystal symmetry of enstatite. Pressures are determined using the ruby fluorescence method [Mao et al., 1986] (below 4.6 GPa where $\mathrm{Ne}$ is in the liquid state) and from the $\mathrm{Ne}$ unit cell volume using the BM3 EOS determined from Dewaele et al. [2008] (above $4.6 \mathrm{GPa}$ ). The pressures determined from each gauge agree up to $15 \mathrm{GPa}$ and then diverge. From the diffraction patterns, one structural transition can be identified between 10.1 and $12.2 \mathrm{GPa}$. This transition pressure is consistent with previous experimental observations using synchrotron Mössbauer spectroscopy [Zhang et al., 2011], XRD [Kung et al., 2004; Zhang et al., 2012], ultrasonic interferometry [Kung et al., 2004], and theoretical calculations [Jahn, 2008]. Below $10.1 \mathrm{GPa}$, the diffraction peaks in the $2 \theta$ range between $7^{\circ}$ and $12^{\circ}$ can be indexed with $P b c a$ symmetry. At pressures higher than $10.1 \mathrm{GPa}$, peaks from a new phase emerge in the XRD patterns, and at pressures higher than $12.2 \mathrm{GPa}$, the diffraction peaks indicate that the sample is converted to a new phase. In the $2 \theta$ range between $7^{\circ}$ and $12^{\circ}$, the diffraction peaks can be indexed using a monoclinic structure with space group $P 2_{1} / c$ (Figure 1), identified in a recent single-crystal XRD study on $\left(\mathrm{Mg}_{1.74} \mathrm{Fe}_{0.16} \mathrm{Al}_{0.05} \mathrm{Ca}_{0.04} \mathrm{Cr}_{0.02}\right)\left(\mathrm{Si}_{1.94} \mathrm{Al}_{0.06}\right) \mathrm{O}_{6}$ [Zhang et al., 2012]. Therefore, we adopt the $P 2_{1} / c$ structure as the structure for our high-pressure phase. The $P 2_{1} / c$ structure is very similar to the $P 2{ }_{1} \mathrm{Ca}$ structure, which is a suggested high-pressure symmetry for enstatite based on molecular dynamics simulations [Jahn, 2008]. In our study, there is a density increase of $1.2 \pm 0.5 \%$ at $10.1 \mathrm{GPa}$ for the $P b c a$ to $P 2_{1} / c$ transition, similar to theoretical results $(\sim 1.3 \%$ [Jahn, 2008]) and a recent single-crystal XRD study $(1.9 \pm 0.5 \%$ over the pressure range of 12.66 to $14.26 \mathrm{GPa}$ [Zhang et al., 2012]). The density increase for the Pbca to $C 2 / \mathrm{c}$ transition in the $\mathrm{Mg}$ end-member is reported to be 3 to 4\% [Kung et al., 2004].

[13] In order to determine the isothermal bulk modulus $\left(K_{T}\right)$ and the corresponding pressure derivative $\left(K_{T}^{\prime}\right)$ of the En87 sample, third-order Birch-Murnaghan equations of state were used to fit the P-V data sets (Figure 2 and Table 1). The OEN phase (Pbca) and the high-pressure phase (hereafter referred to as HP, space group $P 2_{1} / c$ ) were fit separately. For OEN, we obtained for the zero-pressure unit cell volume $\left(\mathrm{V}_{0}\right)$ the same value as our measured value $\left(836 \pm 3 \AA^{3}\right)$ and a zero-pressure bulk modulus $\left(K_{T 0}\right)$ of $103 \pm 5 \mathrm{GPa}$, roughly consistent with previous studies on OEN (Table 2) [Hugh-Jones and Angel, 1997; Flesch et al., 


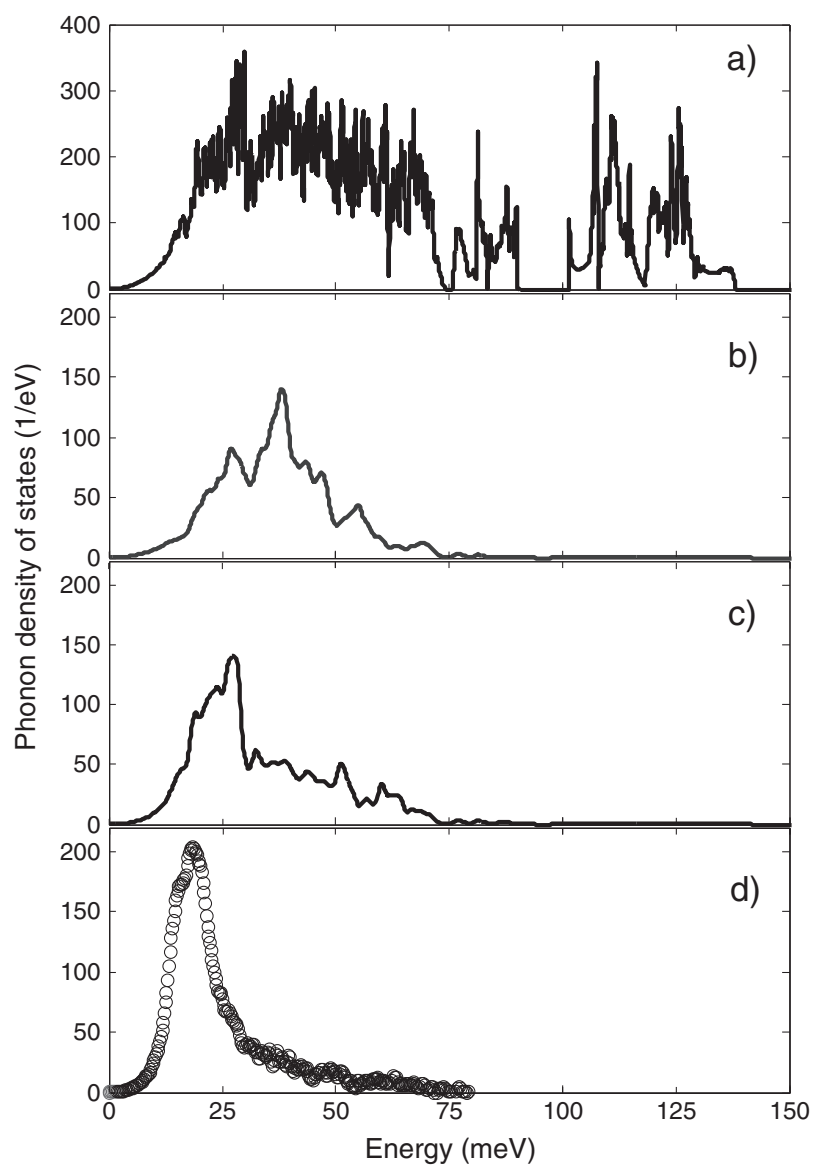

Figure 5. The DFT-calculated phonon DOS (at $0 \mathrm{~K}$ ) and measured Fe partial projected phonon DOS for OEN at ambient pressure (at $300 \mathrm{~K}$ ): (a) total phonon DOS of $\mathrm{Mg}_{2} \mathrm{Si}_{2} \mathrm{O}_{6}$ OEN, (b) partial phonon DOS for $25 \% \mathrm{Mg}$ replaced by $\mathrm{Fe}$ on the M1 site, (c) partial phonon DOS for $25 \% \mathrm{Mg}$ replaced by Fe on the M2 site, and (d) measured Fe partial projected phonon DOS for En87 at $300 \mathrm{~K}$ [Jackson et al., 2009].

1998; Angel and Jackson, 2002; Kung et al., 2004]. The disagreement with the study by Chai et al. [1997] is likely due to the fact that their sample contained more $\mathrm{Al}$ (Table 2). For the pressure derivative of the bulk modulus $\left(K_{T 0}^{\prime}\right)$, we obtained $13 \pm 2$, consistent with the trend in the normalized pressure $\left(\mathrm{F}_{e}\right)$ versus Eulerian finite strain $\left(\mathrm{f}_{e}\right)$ (Figure 2). Although this value is higher than previous reports (Table 2), one must recognize the strong correlation between $K_{T 0}$ and $K_{T 0}^{\prime}$ (Figure 3).

[14] For the HP phase $\left(P 2_{1} / c\right)$, the best fit volume at $12 \mathrm{GPa}$ is $767 \pm 3 \AA^{3}$. The best fit bulk modulus of the $P 2_{1} / c$ phase at $12 \mathrm{GPa}$ is $220 \pm 10 \mathrm{GPa}$, significantly higher than the $C 2 / \mathrm{c}$-structured $\mathrm{Mg}$ end-member at the same pressure (168 \pm 17 [Shinmei et al., 1999], $177 \pm 6$ [Angel and Hugh-Jones, 1994], and $186 \pm 1 \mathrm{GPa}$ [Kung et al., 2005]). The best fit $K_{T}^{\prime}$ at $12 \mathrm{GPa}$ is $8 \pm 4$. The $68 \%$ confidence ellipses for the $K_{T}$ and the $K_{T}^{\prime}$ fitting are shown in Figure 3. The confidence ellipses show that $K_{T}$ and $K_{T}^{\prime}$ are strongly correlated [Angel, 2000]. We note that our equations of state for both phases should not be extrapolated outside the measured pressure ranges for each phase (see Figure 3).

\subsection{Nuclear Resonant Inelastic X-Ray Scattering and First-Principles Calculations}

[15] NRIXS measurements provide an independent method to examine the elastic properties of a sample. A quasi-harmonic model was used to extract the partial projected phonon density of states (DOS) (Figure 4) from the measured raw NRIXS spectra [Sturhahn, 2000]. With increasing pressure, the DOS expands and shifts toward higher phonon energies, with subtle changes in shape. From the integration of the DOS, one obtains parameters related to the ${ }^{57} \mathrm{Fe}$-participating lattice vibrations in the En87 sample: the Lamb-Mössbauer factor, $\mathrm{f}_{\mathrm{LM}}$ (related to the mean square displacement of the iron atoms); the mean force constant, $\mathrm{D}_{\text {ave }}$; the vibrational free energy per atom, $F_{\text {vib }}$; the vibrational kinetic energy per atom, $\mathrm{E}_{k}$; the vibrational specific heat at constant volume per atom, $\mathrm{c}_{V}$; and the vibrational entropy per atom, $\mathrm{S}_{\mathrm{vib}}$ [Sturhahn, 2000] (Table 3). A subset of these parameters show a minor change in the range of 10.1 to $12.2 \mathrm{GPa}$, thus indicating some level of sensitivity to the transition.

[16] We compare the ambient phonon DOS from the NRIXS measurement [Jackson et al., 2009] with the phonon density of states calculated from ab initio DFT [Caracas and Gonze, 2010]. For this, we consider three possible cases in the DFT calculations: pure $\mathrm{Mg}_{2} \mathrm{Si}_{2} \mathrm{O}_{6}, 25 \% \mathrm{Fe}$ on the M1 site, and $25 \% \mathrm{Fe}$ on the $\mathrm{M} 2$ site. The theoretical total phonon DOS and partial phonon DOS are shown in Figure 5. The measured partial phonon DOS from NRIXS is very similar to the DFT calculation of the partial phonon DOS where the Fe atoms are only in the M2 site (Figures 4 and 5): both have intense phonon peaks around $20 \mathrm{meV}$, and neither has large intensity around $40 \mathrm{meV}$. Therefore, the NRIXS data and DFT calculations suggest that the Fe occupation (or more accurate, that the heavier mass element) in the En87 sample is primarily in the M2 site, consistent with synchrotron and conventional Mössbauer studies that $92 \%$ of the ${ }^{57} \mathrm{Fe}$ occupies the M2 site [Zhang et al., 2011; Jackson et al., 2009]. Using PHOENIX, we input the various DFTcomputed phonon DOSs and calculate the above mentioned parameters at 0 and $300 \mathrm{~K}$ for the different considerations of Fe site occupancy (Table 4). Note that the average force constant is independent of temperature. It is not surprising that the parameters are not in good agreement with the experiments, as we consider heavy $\mathrm{Mg}$ as a proxy for $\mathrm{Fe}$ in our DFT calculations. It is possible to explore the possibility of scaling the DFT-computed DOSs to obtain better agreement. However, this particular exercise would only make sense if the phonon DOSs were computed with Fe, rather than heavy Mg. The absolute values of the free energy may be off significantly, but it is the volume derivative of the free energy that should be compared in this case, and that was not computed by DFT in this study.

[17] By analyzing the low-energy region of the measured partial phonon DOS, one can obtain the Debye sound velocity $\left(V_{D}\right)$ of the sample. The Debye sound velocity is the isotropic sound velocity of the material, obtained from the region in the DOS where the dispersion of the acoustic modes is linear (or the DOS is parabolic) as a function of energy. The energy range that provided the best fit is from 3.7 to $12.2 \mathrm{meV}$ (Figure 6). This range avoids the elastic peak (resolution function) at lower energies [Sturhahn and Jackson, 2007; Jackson 
Table 2. Unit Cell Volume, Isothermal Bulk Modulus, and Its Pressure Derivative of Orthoenstatite $(\mathrm{Pbca})$ at Room Pressure and Temperature From Different Experimental Studies ${ }^{\mathrm{a}}$

\begin{tabular}{lccccccc}
\hline & & & & En87 & & \\
& En100 $^{\mathrm{b}}$ & En100 $^{\mathrm{c}}$ & En100 $^{\mathrm{d}}$ & (This Study) $^{\text {En85 }}$ & En83 $^{\mathrm{f}}$ & En82 $^{\mathrm{g}}$ \\
\hline $\mathrm{V}_{0}\left(\AA^{3}\right)$ & $832.5(2)$ & $832.9(1)$ & $839(8)$ & $836(3)$ & $833.9(2)$ & $833.12(6)$ & $834.1(5)$ \\
$K_{T 0}(\mathrm{GPa})$ & $105.8(5)$ & $109(4)^{*}$ & $104(2)^{*}$ & $103(5)$ & $109(2)$ & $112(1)$ & $115.5(5)$ \\
$K_{T}^{\prime}$ & $8.5(3)$ & $6.6(7)^{*}$ & $10.9(5)^{*}$ & $13(2)$ & $9(1)$ & $7.4(4)$ & 7.82 \\
Method & XRD+BS & XRD+UI & UI & XRD & XRD & XRD & ISLS \\
\hline
\end{tabular}

\footnotetext{
${ }^{a}$ Values in parentheses indicate the uncertainty in the last significant digit. Errors presented in this study are at the $1 \sigma$ level. BS: Brillouin spectroscopy; UI: ultrasonic interferometry; ISLS: impulsive stimulated light spectroscopy. $\left(^{*}\right)$ indicates adiabatic values: $K_{S 0}$ is $\sim 1 \%$ higher than $K_{T 0}$ [Angel and Jackson, 2002].

et al., 2009]. We compare the Debye sound velocity in this study with the calculated values from previous studies on enstatite (Figure 7a). For previous single-crystal studies [Frisillo and Barsch, 1972; Duffy and Vaughan, 1988; Webb and Jackson, 1993; Chai et al., 1997], the Debye sound velocity was determined numerically from averaging the elastic constants using the Christoffel equation [Sturhahn and Jackson, 2007] or from the isotropic $V_{P}$ and $V_{S}$ values from experiments on powdered material [Flesch et al., 1998; Kung et al., 2004]. One interesting feature is the decrease of $V_{D}$ at around $12 \mathrm{GPa}$, which is observed in our data and Kung et al. [2004]. $V_{D}$ decreases by about $0.2 \mathrm{~km} / \mathrm{s}$ when pressure increases from 10.5 to $12.3 \mathrm{GPa}$. Our in situ XRD pattern shows that there is a transition from the $\mathrm{Pbca}$ structure to a high-pressure phase, and Mössbauer spectroscopy data show a change in the trend of the hyperfine parameters of En87 [Zhang et al., 2011], so it is reasonable to conclude that the decrease in $V_{D}$ is related to the structural transition.

[18] By combining the Debye sound velocity determined from NRIXS and the bulk modulus from the P-V equation of state (all determined in this study on En87 from the same bulk sample), it is possible to extract the compressional $\left(V_{P}\right)$ and shear $\left(V_{S}\right)$ sound velocities of En87 as a function of pressure (Figures $7 \mathrm{~b}$ and $7 \mathrm{c})$. The compressional $\left(V_{P}\right)$ and shear $\left(V_{S}\right)$ sound velocities can be calculated from

$$
\frac{3}{V_{D}^{3}}=\frac{1}{V_{P}^{3}}+\frac{2}{V_{S}^{3}}
$$

Table 3. Thermodynamic Parameters of the ${ }^{57} \mathrm{Fe}$-Participating Vibrations of En87 Determined From NRIXS Spectra at Different Pressures Measured at $300 \mathrm{~K}^{\mathrm{a}}$

\begin{tabular}{lcccccc}
\hline $\begin{array}{l}\text { Pressure } \\
(\mathrm{GPa})\end{array}$ & $\mathrm{f}_{\mathrm{LM}}$ & $\begin{array}{c}F_{\text {vib }} \\
(\mathrm{meV} / \text { atom })\end{array}$ & $\begin{array}{c}\mathrm{D}_{\text {ave }} \\
\left(\times 10^{2} \mathrm{~N} / \mathrm{m}\right)\end{array}$ & $\begin{array}{c}\mathrm{E}_{k} \\
(\mathrm{meV} / \text { atom })\end{array}$ & $\begin{array}{c}\mathrm{c}_{V} \\
\left(\mathrm{k}_{B} / \text { atom }\right)\end{array}$ & $\begin{array}{c}\mathrm{S}_{\text {vib }} \\
\left(\mathrm{k}_{B} / \text { atom }\right)\end{array}$ \\
\hline $0^{\mathrm{b}}$ & $0.730(2)^{\mathrm{b}}$ & $-8.4(3)$ & $1.70(3)^{\mathrm{b}}, 1.70(3)^{\mathrm{c}}$ & $14.01(7)^{\mathrm{b}}$ & $2.75(1)^{\mathrm{b}}$ & $3.60(1)^{\mathrm{b}}$ \\
$3.9(2)$ & $0.755(3)$ & $-3(2)$ & $1.85(27), 1.89(29)^{\mathrm{c}}$ & $14.2(5)$ & $2.72(5)$ & $3.42(4)$ \\
$6.9(4)$ & $0.757(3)$ & $-4(3)$ & $1.70(33), 1.68(34)^{\mathrm{c}}$ & $14.1(6)$ & $2.74(6)$ & $3.45(5)$ \\
$10.5(7)$ & $0.784(3)$ & $4(2)$ & $2.11(22), 2.31(22)^{\mathrm{c}}$ & $14.4(4)$ & $2.68(5)$ & $3.19(4)$ \\
$12.3(7)$ & $0.784(3)$ & $3(2)$ & $2.10(27), 2.10(29)^{\mathrm{c}}$ & $14.4(5)$ & $2.69(5)$ & $3.22(4)$ \\
$17(1)$ & $0.797(3)$ & $7(2)$ & $2.20(23), 1.91(24)^{\mathrm{c}}$ & $14.5(4)$ & $2.67(5)$ & $3.09(4)$ \\
\hline
\end{tabular}

${ }^{\mathrm{a}} \mathrm{f}_{\mathrm{LM}}$ : Lamb-Mössbauer factor; $F_{\mathrm{vib}}$ : free energy; $\mathrm{D}_{\mathrm{ave}}$ : mean force constant; $\mathrm{E}_{k}$ : kinetic energy; $\mathrm{c}_{V}$ : vibrational specific heat; $\mathrm{S}_{\mathrm{vib}}$ : vibrational entropy. All parameters were determined from the partial phonon DOS, unless otherwise noted. Uncertainties were determined using the PHOENIX software [Sturhahn, 2000]. Pressures determined from in situ volume measurements of enstatite at 3-ID-B and the BM3 EOS (see text).

${ }^{\mathrm{b}}$ Jackson et al. [2009].

${ }^{\mathrm{c}}$ Determined after refinement of the raw data.

$$
\frac{K}{\rho}=V_{P}^{2}-\frac{4}{3} V_{S}^{2}
$$

where $\rho$ is the density (corrected for ${ }^{57} \mathrm{Fe}$ enrichment), $K$ is the bulk modulus from the equation of state, and $V_{D}$ is the Debye sound velocity from the NRIXS measurement. In the calculation, the in situ XRD density and the bulk modulus from the best fit third-order Birch-Murnaghan EOS are used. is case, we assume that $K_{S 0}$ can be approximated by $K_{T 0}$ ( $K_{S 0}$ is $\sim 1 \%$ higher than $K_{T 0}$ [Angel and Jackson, 2002]). The associated uncertainties in determining $V_{P}$ and $V_{S}$ from $V_{D}$ and the bulk modulus have been discussed in detail in and Jackson [2007].

[19] We compare our results with previous studies [Frisillo and Barsch, 1972; Duffy and Vaughan, 1988; Webb and Jackson, 1993; Chai et al., 1997; Flesch et al., 1998; ing et al., 2004; Jackson et al., 2009] (Figures 7b and Nete that the ambient pressure results of En87 are from NRIXS measurements on a larger aggregate of the sample [Jackson et al., 2009], from which a smaller portion of the sample was drawn for this study. Therefore, the room value of En 87 is a very good representation of the average properties of En87 at this pressure. The values of En87 are consistent with a decrease in wave speed with the addition of iron at a given pressure; however, there wears to be an inconsistency in the magnitude of the trend when comparing results from different techniques [Duffy and Vaughan, 1988; Chai et al., 1997; Flesch et al., 1998; Kung et al., 2004; Jackson et al., 2009, 1999]. In the pres- 
Table 4. Thermodynamic Parameters Determined From the DFT-Computed Phonon DOS, Calculated at 0 and 300 K Using PHOENIX

\begin{tabular}{lcccccc}
\hline DFT phonon DOS & $\mathrm{f}_{L M}$ & $\begin{array}{c}F_{\text {vib }} \\
(\mathrm{meV} / \text { atom })\end{array}$ & $\begin{array}{c}\mathrm{D}_{\text {ave }} \\
\left(\times 10^{2} \mathrm{~N} / \mathrm{m}\right)\end{array}$ & $\begin{array}{c}\mathrm{E}_{k} \\
(\mathrm{meV} / \text { atom })\end{array}$ & $\begin{array}{c}\mathrm{c}_{V} \\
\left(\mathrm{k}_{B} / \text { atom }\right)\end{array}$ & $\begin{array}{c}\mathrm{S}_{\text {vib }} \\
\left(\mathrm{k}_{B} / \text { atom }\right)\end{array}$ \\
\hline $\begin{array}{l}\mathrm{Mg}_{2} \mathrm{Si}_{2} \mathrm{O}_{6} \text { total phonon DOS, Figure 5a } \\
\begin{array}{l}\text { Fe partial phonon DOS, Figure 5b } \\
\text { 25\% Fe in the M1-site only }\end{array}\end{array}$ & $\mathrm{NA}$ & $89.7,72.6$ & $10.31,10.31$ & $14.9,19.2$ & $0,2.0$ & $0,1.7$ \\
$\begin{array}{l}\text { Fe partial phonon DOS, Figure 5c } \\
\text { 25\% Fe in the M2-site only }\end{array}$ & $0.94,0.86$ & $57.5,31.5$ & $3.51,3.51$ & $9.4,15.4$ & $0,2.5$ & $0,2.3$ \\
\hline
\end{tabular}

${ }^{a} \mathrm{f}_{L M}$ : Lamb-Mössbauer factor; $F_{v i b}$ : free energy; $\mathrm{D}_{a v e}$ : mean force constant; $\mathrm{E}_{k}$ : kinetic energy; $\mathrm{c}_{V}$ : vibrational specific heat; $\mathrm{S}_{v i b}:$ vibrational entropy. NA: not applicable. In the case of the total phonon DOS, the values represent contributions from all atoms in the lattice. For the partial phonon DOS, the values represent contributions from the ${ }^{57} \mathrm{Fe}$-participating vibrations. All parameters are determined using the PHOENIX software at 0 and $300 \mathrm{~K}$, respectively [Sturhahn, 2000].

sure range where we observe OEN $(P b c a)$, the $V_{D}, V_{P}$, and $V_{S}$ increase from room pressure to $10.5 \mathrm{GPa}$. These trends are consistent with previous measurements in this pressure range [Frisillo and Barsch, 1972; Webb and Jackson, 1993; Chai et al., 1997; Flesch et al., 1998; Kung et al., 2004]. The pressure derivative of the shear modulus for the $\mathrm{Pbca}$ phase is $\mathrm{d} \mu / \mathrm{dP}=1.7 \pm 0.1$ between 0 and $10.5 \mathrm{GPa}$.

[20] Near the phase transition (10.5 GPa), our in situ XRD pattern at sector 3-ID-B showed that the Pbca phase is dominant. A weak $P 2_{1} / c(32 \overline{1})$ peak is present at this pressure; however, there is not enough information to resolve its in situ density nor the abundance of the $P 2_{1} / c$ phase. Therefore, we report the sound velocities at $10.5 \mathrm{GPa}$ using the density and bulk modulus from the dominant $\mathrm{Pbca}$ phase. If one uses the density and bulk modulus of the $P 2_{1} / c$ phase,

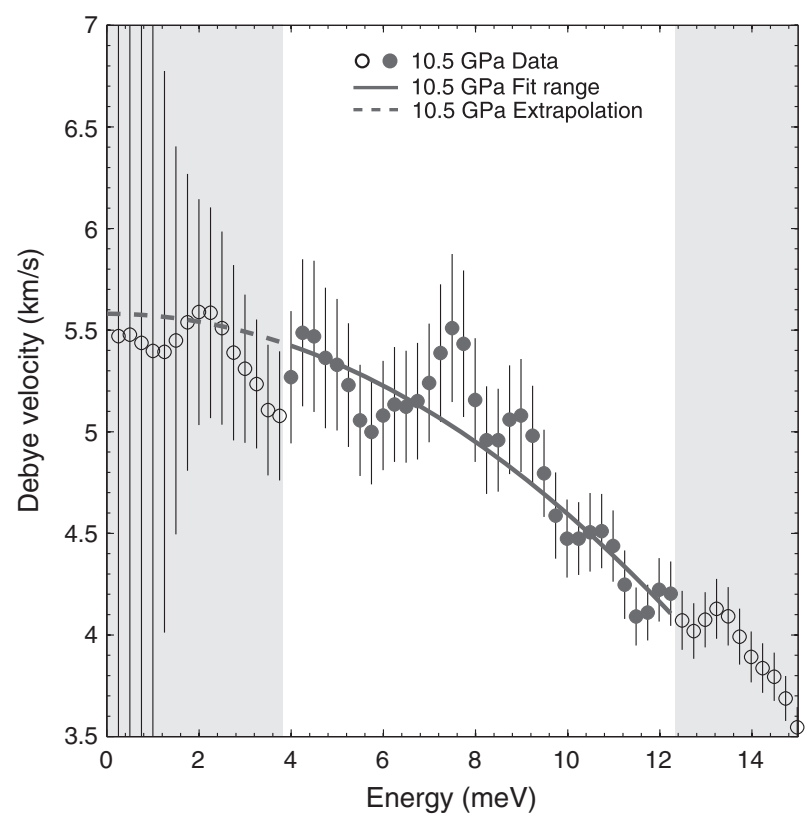

Figure 6. Debye sound velocity $\left(V_{D}\right)$ determination at 10.5 GPa. The fit (solid and dashed lines) was performed on the data (open circles) starting from $3.7 \mathrm{meV}$ (determined by the resolution of the monochrometer) and ending at $12.2 \mathrm{meV}$ (determined by chi-square analysis) and then extrapolated to $\mathrm{E}=0$ to determine $V_{D}$. Gray regions show the data and associated uncertainties that were not used in the fit. the compressional and shear velocities of En87 are within the uncertainties of the Pbca phase at $10.5 \mathrm{GPa}$.

[21] At $12.3 \mathrm{GPa}$, the (421) peak of the HP phase appears and $V_{D}$ and $V_{S}$ for $P 2_{1} / c$ show a drop in velocity (a decrease of $\sim 0.2 \mathrm{~km} / \mathrm{s}, \sim 4 \%$ in $V_{S}$ ), rather than a smooth increase (Figure 7). A similar drop in $V_{S}$ was observed in the Mg endmember using ultrasonic interferometry [Kung et al., 2004]. This behavior is likely related to the structural transition. Interestingly, we do not observe the same decrease in $V_{P}$ as past studies have reported for the $\mathrm{Mg}$ end-member. The $V_{P}$ value up to $12.3 \mathrm{GPa}$ is similar to the values reported by Chai et al. [1997]. In our XRD measurements performed on a sample from the same run charge (Figures 1 and 2), we find that the $P b c a-P 2_{1} / c$ structural transition is associated with a volume reduction, which leads to a determined $V_{P}$ value that shows a slight change in trend near the transition. We show that the $\mathrm{Fe}$ atoms are almost entirely in the M2 site, using a combination of Mössbauer spectroscopy, NRIXS, and DFT (Figure 5). Differences in Fe concentration, Fe ordering, and equations of state for the different enstatite samples could, in part, explain the differences in $V_{P}$ between the studies.

\subsection{Geophysical Implications}

[22] Phase transitions of enstatite have been suggested as candidates for the seismic $\mathrm{X}$ discontinuity in a depleted mantle [Woodland and Angel, 1997; Woodland, 1998; Kung et al., 2004, 2005; Akashi et al., 2009; Jacobsen et al., 2010]. In seismological studies, the $X$ discontinuity is characterized by a large depth variation, from 240 to $340 \mathrm{~km}$ [Deuss and Woodhouse, 2002; Revenaugh and Jordan, 1991; Bagley and Revenaugh, 2008], with reflections associated with a shear impedance increase of 3 to $7.5 \%$ (corresponding to a reflection coefficient of 1.5 to $3.8 \%$ [Revenaugh and Jordan, 1991; Bagley and Revenaugh, 2008]). The compressional impedance change for this discontinuity is not clear yet. In our study, we identify a transition occurring in enstatite, likely $P b c a-P 2 / c$, between 10.1 and $12.2 \mathrm{GPa}$ (a depth equivalent of 300-350 km) accompanied by a shear impedance drop of $\sim 2 \%$. The shear impedance of the $P 2{ }_{1} / c$ phase increases by $\sim 8 \%$ from 12.3 to $17 \mathrm{GPa}$. The compressional impedance of enstatite slightly increases by $\sim 2 \%$ for the $P b c a-P 2_{1} / c$ transition between 10.1 and $12.3 \mathrm{GPa}$, and it continues to increase by $\sim 7 \%$ from 12.3 to $17 \mathrm{GPa}$. Molecular dynamics simulation [Jahn, 2008] suggests that the $P 2_{1} / c$ phase of the $\mathrm{Mg}$ end-member is metastable at high temperature, and multianvil experiments show that the 

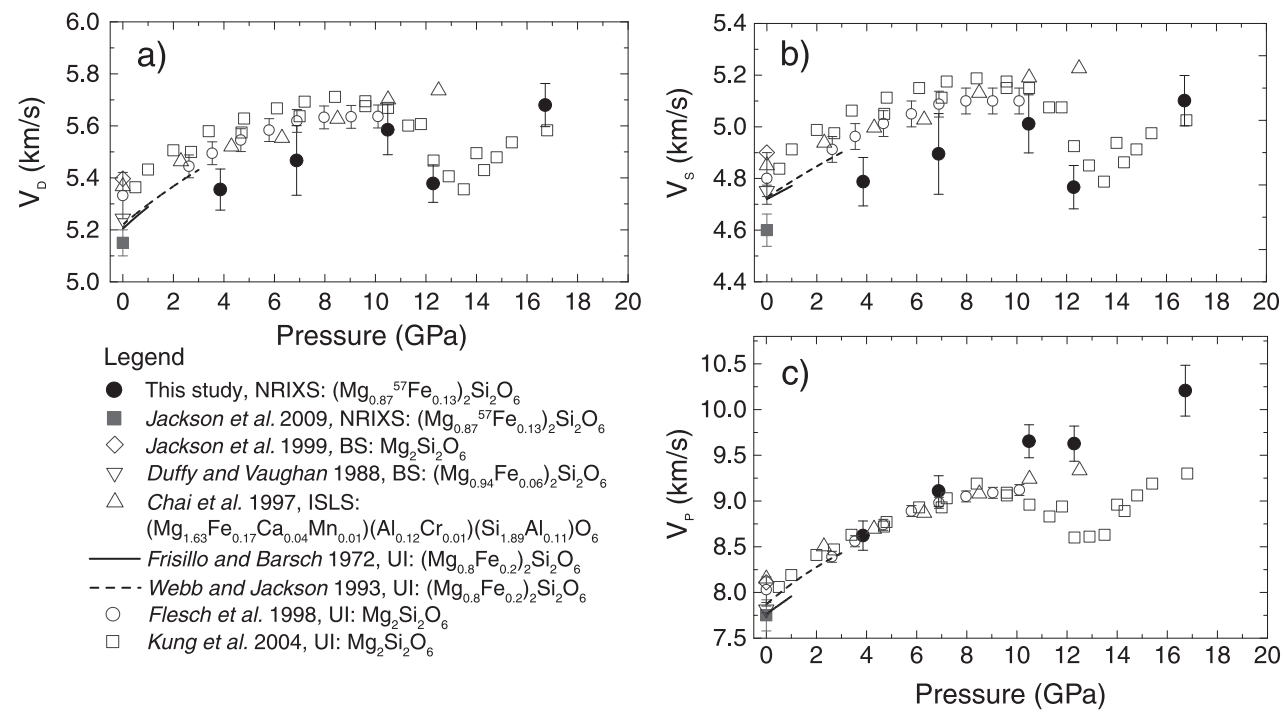

Figure 7. Sound velocities determined from this experiment (see Table 5) and from previous measurements (see Legend). (a) Debye velocity $\left(V_{D}\right)$, (b) shear velocity $\left(V_{S}\right)$, and (c) compressional velocity $\left(V_{P}\right)$. UI: ultrasonic interferometry; BS: Brillouin spectroscopy; ISLS: impulsive stimulated light spectroscopy.

$\mathrm{Mg}$ end-member HP-CEN phase is the stable polymorph of enstatite at $14 \mathrm{GPa}$ and $1000^{\circ} \mathrm{C}$ [Kung et al., 2004]. We explore the influence of iron-bearing Pbca-structured enstatite on upper mantle petrologic models, as well as the high-pressure phases of enstatite, and compare these results to seismic observations. Specifically, we focus on the shear properties, as these are well resolved in NRIXS studies (equation 1).

[23] We construct shear velocity profiles for candidate upper mantle assemblages that include $\mathrm{Pbca}$-structured enstatite, HP-CEN, and $P 2_{1} / c$-structured enstatite. We use a finite strain method [Duffy and Anderson, 1989] to primarily assess the influence of $P b c a$-structured enstatite on seismic shear wave structures that have been reported. For the elastic moduli and associated pressure derivatives of enstatite, we use values from this study. We use the thermal expansion coefficient and linear temperature derivatives of the elastic moduli of the Pbca phase from Jackson et al. [2007]. Thermoelasticity data for olivine $\left(\left(\mathrm{Mg}_{0.9} \mathrm{Fe}_{0.1}\right)_{2} \mathrm{SiO}_{4}\right), C 2 / c \mathrm{HP}$ CEN, diopside, and pyrope garnet $\left(\left(\mathrm{Mg}_{0.9} \mathrm{Fe}_{0.1}\right)_{3} \mathrm{Al}_{2}\left(\mathrm{SiO}_{4}\right)_{3}\right)$ were taken from recent reports [Wang et al., 1998; Liu et al., 2005; Kung et al., 2005; Isaak et al., 2006; Zou et al., 2012]
(Table 6). We use a $1400^{\circ} \mathrm{C}$ adiabat in the calculation. Three different petrological models were considered: pyrolite-like with $57 \%$ olivine, $14 \%$ pyrope garnet, $12 \%$ diopside, and $17 \%$ enstatite (volume ratio) [Ringwood, 1991]; enstatiteenriched harzburgite with $50 \%$ olivine, $10 \%$ pyrope garnet, and 40\% enstatite [Irifune and Ringwood, 1987; Hieronymus et al., 2007]; and piclogite-like with $16 \%$ olivine, $37 \%$ pyrope garnet, $23 \%$ diopside, $21 \%$ jadeite (assume to have the same elastic parameters as diopside), and 3\% enstatite [Bass and Anderson, 1984; Ita and Stixrude, 1992] (Figure 8).

[24] We find that the characteristic shear velocities for these three petrological models between 230 and $280 \mathrm{~km}$ depths are lower than the global average PREM model [Dziewonski and Anderson, 1981] and higher than the global average AK135 model [Kennett et al., 1995]. It is noteworthy to point out that in this depth region, the average Earth models PREM and AK135 show significantly different wave speeds and gradients (Figure 8). The shear velocities of the petrological models are slightly lower than the shear structure beneath tectonically stable regions such as the eastern North American continent at depths above

Table 5. Elastic Parameters of En 87 Determined From This Study Using XRD and NRIXS at Different Pressures ${ }^{\mathrm{a}}$

\begin{tabular}{lcccccccccc}
\hline $\begin{array}{l}\text { Volume } \\
\left(\AA^{3}\right)\end{array}$ & $\begin{array}{c}\text { Density } \\
\left(\mathrm{g} / \mathrm{cm}^{3}\right)\end{array}$ & $\begin{array}{c}\text { Pressure } \\
(\mathrm{GPa})\end{array}$ & $\begin{array}{c}V_{D} \\
(\mathrm{~km} / \mathrm{s})\end{array}$ & $\begin{array}{c}V_{P} \\
(\mathrm{~km} / \mathrm{s})\end{array}$ & $\begin{array}{c}V_{S} \\
(\mathrm{~km} / \mathrm{s})\end{array}$ & $\begin{array}{c}V_{\Phi} \\
(\mathrm{km} / \mathrm{s})\end{array}$ & $\frac{V_{P}}{V_{S}}$ & $v$ & $\begin{array}{c}K \\
(\mathrm{GPa})\end{array}$ & $\begin{array}{c}\mu \\
(\mathrm{GPa})\end{array}$ \\
\hline $836(3)^{\mathrm{b}}$ & $3.31(1)$ & 0 & $5.12(5)$ & $7.7(2)$ & $4.63(5)$ & $5.6(2)$ & 1.669 & 0.220 & $103(5)$ & $71(2)$ \\
$811(2)$ & $3.41(2)$ & $3.9(2)$ & $5.33(8)$ & $8.6(2)$ & $4.78(8)$ & $6.6(2)$ & 1.794 & 0.274 & $147(9)$ & $78(2)$ \\
$795(3)$ & $3.48(3)$ & $6.9(4)$ & $5.5(1)$ & $9.1(2)$ & $4.9(1)$ & $7.1(2)$ & 1.862 & 0.297 & $177(9)$ & $83(4)$ \\
$782(2)$ & $3.54(3)$ & $10.5(7)$ & $5.55(9)$ & $9.6(2)$ & $4.96(9)$ & $7.7(3)$ & 1.935 & 0.318 & $210(10)$ & $87(3)$ \\
$767(3)$ & $3.61(3)$ & $12.3(7)$ & $5.38(7)$ & $9.6(2)$ & $4.79(7)$ & $7.8(3)$ & 2.001 & 0.332 & $220(10)$ & $83(2)$ \\
$752(3)$ & $3.68(3)$ & $17(1)$ & $5.68(8)$ & $10.2(3)$ & $5.05(8)$ & $8.4(5)$ & 2.025 & 0.339 & $260(20)$ & $94(3)$ \\
\hline
\end{tabular}

${ }^{a} V_{D}, V_{P}, V_{S}$, and $V_{\Phi}$ : Debye, compressional, shear, and bulk sound velocities, respectively; $K$ : bulk modulus; $\mu$ : shear modulus. Volume was determined by in situ XRD at APS 3-ID-B (Figure 1b, see text), and density was corrected for ${ }^{57} \mathrm{Fe}$ enrichment. Pressures up to $10.5 \mathrm{GPa}$ were determined from the Pbca EOS (Table 2), and at 12.3 and $17 \mathrm{GPa}$, the $P 2_{1} / c$ EOS was used. Error determinations: volume - statistical, density-volume and microprobe uncertainties, $K$-BM3 fit at the $1 \sigma$ level, other parameters-PHOENIX software [Sturhahn, 2000].

${ }^{\mathrm{b} J a c k s o n}$ et al. [2009], recalculated $V_{P}, V_{S}, K$, and $\mu$ using the $P b c a$ EOS from this study. 
Table 6. Thermoelastic Parameters of Minerals Used in the Finite Strain Model ${ }^{\mathrm{a}}$

\begin{tabular}{|c|c|c|c|c|c|c|c|c|c|c|}
\hline Minerals & $\begin{array}{c}\rho_{0} \\
\left(\mathrm{~g} / \mathrm{cm}^{3}\right)\end{array}$ & $\begin{array}{c}K \\
(\mathrm{GPa})\end{array}$ & $\begin{array}{c}\mu \\
(\mathrm{GPa})\end{array}$ & $K^{\prime}$ & $\mu^{\prime}$ & $\begin{array}{c}\mathrm{d} K / \mathrm{dT} \\
(\mathrm{GPa} / \mathrm{K})\end{array}$ & $\begin{array}{c}\mathrm{d} \mu / \mathrm{dT} \\
(\mathrm{GPa} / \mathrm{K})\end{array}$ & $\begin{array}{c}\alpha_{0} \\
\left(10^{-6} \mathrm{~K}^{-1}\right)\end{array}$ & $\begin{array}{c}\alpha_{1} \\
\left(10^{-9} \mathrm{~K}^{-2}\right)\end{array}$ & Reference \\
\hline OEN & $3.31(1)^{\mathrm{b}}$ & $103(5)^{\mathrm{b}}$ & $71(2)^{b}$ & $13(2)^{b}$ & $1.7(1)^{\mathrm{b}}$ & $-0.0263(3)^{\mathrm{c}}$ & $-0.0136(3)^{\mathrm{c}}$ & $29.7^{\mathrm{c}}$ & $5.7^{\mathrm{c}}$ & $\begin{array}{c}\text { This study }{ }^{\mathrm{b}} \\
\text { Jackson et al. }[2007]^{\mathrm{c}}\end{array}$ \\
\hline$P 2_{1} / c$ & $3.61(3)^{\mathrm{b}}$ & $220(10)^{b}$ & $83(2)^{b}$ & $8(4)^{b}$ & $2.5(5)^{\mathrm{b}}$ & $-0.0263(3)^{\mathrm{c}}$ & $-0.0136(3)^{\mathrm{c}}$ & $29.7^{\mathrm{c}}$ & $5.7^{\mathrm{c}}$ & $\begin{array}{l}\text { This study at } 12 \mathrm{GPa}^{\mathrm{b}} \\
\text { Jackson et al. }[2007]^{\mathrm{c}}\end{array}$ \\
\hline HP-CEN & $3.46(1)$ & $156(1)$ & $99(1)$ & $5.6(3)$ & $1.5(1)$ & $-0.017(1)$ & $-0.015(1)$ & $17.3(80)$ & $16.4(11.7)$ & $\begin{array}{c}\text { Kung et al. }[2005] \\
\text { at } 6.5 \mathrm{GPa}\end{array}$ \\
\hline Olivine & $3.342(2)$ & $130.3(4)$ & $77.4(2)$ & $4.61(11)$ & $1.61(4)$ & $-0.0164(5)$ & $-0.0130(3)$ & 27.11 & 6.885 & Liu et al. [2005] \\
\hline Garnet & $3.566(1)^{\mathrm{d}}$ & $170.0(2)^{\mathrm{d}}$ & $93.2(1)^{d}$ & $4.51(2)^{d}$ & $1.51(2)^{d}$ & $-0.0170(1)^{d}$ & $-0.0107(1)^{\mathrm{d}}$ & $23(2)^{\mathrm{e}}$ & $9.4(2.8)^{\mathrm{e}}$ & $\begin{array}{c}\text { Zou et al. }[2012]^{\mathrm{d}} \\
\text { Wang et al. }[1998]^{\mathrm{e}}\end{array}$ \\
\hline Diopside & $3.277(5)$ & $115.9(9)$ & $72.8(4)$ & $4.5(1.8)$ & 1.7 & -0.0123 & -0.00998 & 26 & 10 & Isaak et al. [2006] \\
\hline
\end{tabular}

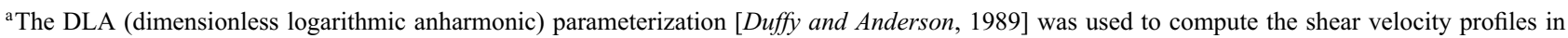
Figure 8 . The thermal expansion coefficients $\left(\alpha_{0}\right.$ and $\left.\alpha_{1}\right)$ were used to correct the densities and pressure derivatives of elastic moduli. For the high-pressure phases $\left(P 2_{1} / c\right.$ and HP-CEN), the thermoelastic parameters were first projected back to ambient P-T values using the third-order finite strain theory without a temperature correction, and then the projected ambient values were treated the same as the other phases. To compute the velocities of the rock, the average sound velocities were calculated using the Voigt-Reuss-Hill procedure and the Hill average is plotted in Figure 8.

${ }^{b-e}$ Denotes the associated source reference listed in the last column.

$300 \mathrm{~km}$ (SNA [Grand and Helmberger, 1984a]). In the same depth range, they are significantly higher $(>50 \mathrm{~m} / \mathrm{s})$ than the shear velocity structure beneath tectonically active regions such as the western United States (TNA [Grand and Helmberger, 1984a]), the Pacific Ocean (PAC06 [Tan and Helmberger, 2007]), and the northern Atlantic Ocean (ATL [Grand and Helmberger, 1984b]) (Figure 8). The calculated pressure derivative of the shear wave speed $\left(\mathrm{d} V_{S} / \mathrm{dP}\right)$ is about $0.03 \mathrm{~km} / \mathrm{s} / \mathrm{GPa}$ between 230 and $300 \mathrm{~km}$ for these three petrological models. This shear velocity gradient is higher than the average Earth model PREM but lower than regional studies. Based on the phase diagram of enstatite [Woodland, 1998], we assume that the OEN phase ( $\mathrm{Pbca}$ ) transitions into the HP-CEN phase $(C 2 / c)$ at $300 \mathrm{~km}(\sim 10 \mathrm{GPa})$, accompanied by a shear velocity jump [Kung et al., 2005]. It is possible to calculate the shear reflection coefficients, $R$, for the different petrologies considered here from the shear velocity and density of OEN (this study) and HP-CEN [Kung et al., 2005] using the following equation [Revenaugh and Jordan, 1991; Bagley and Revenaugh, 2008]:

$$
R=\frac{\rho_{\mathrm{HP}-\mathrm{CEN}} \times V_{\mathrm{HP}-\mathrm{CEN}}-\rho_{\mathrm{OEN}} \times V_{\mathrm{OEN}}}{\rho_{\mathrm{HP}-\mathrm{CEN}} \times V_{\mathrm{HP}-\mathrm{CEN}}+\rho_{\mathrm{OEN}} \times V_{\mathrm{OEN}}}
$$

[25] The shear reflection coefficients corresponding to different petrological compositions are $0.5 \%$ (pyrolite), $1.2 \%$ (enstatite-enriched harzburgite), and $0.1 \%$ (piclogite) at $300 \mathrm{~km}$ depth. The calculated shear reflection coefficients are lower than seismic observations for the " $\mathrm{X}$ discontinuity" (1.5 to 3.5\%) [Revenaugh and Jordan, 1991; Bagley and Revenaugh, 2008]. Based on our XRD and NRIXS data, we also compute the shear velocity profile of the pyrolytic mantle, speculating that the $P b c a$ phase gradually transitions into the $P 2_{1} / c$ phase from 10 to $12 \mathrm{GPa}$ (Figure 8). We note that the existence of the $P 2_{1} / c$ phase in the mantle remains speculative.

[26] Although iron-bearing enstatite-rich phase assemblages may produce lower than average shear velocities, it appears that between 250 and $300 \mathrm{~km}$ depths in tectonically active regions, changes in candidate petrologic assemblies (i.e., pyrolite, piclogite, and harzburgite) may not be enough to explain the very low shear velocities observed. Partial melting [Tan and Helmberger, 2007] or a hydrated phase assemblage may help explain the nonpervasive distribution of the X discontinuity [Jacobsen et al., 2010; Revenaugh and Jordan, 1991]. However, observations of the X discontinuity in regions expected to be dry, such as the underside region

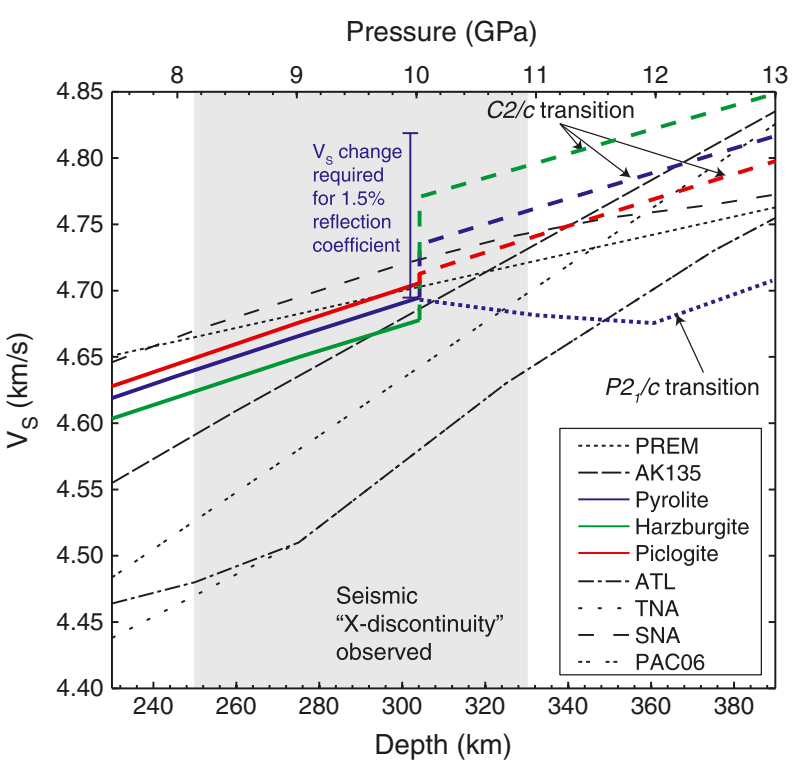

Figure 8. Comparison of calculated shear wave velocities from candidate upper mantle petrological models $\left(1400^{\circ} \mathrm{C}\right.$ adiabat; see text) with seismic profiles. At $\mathrm{P}>$ $10 \mathrm{GPa}$ : assuming $\mathrm{C} 2 / \mathrm{c}$ transition (dashed curve) [Kung et al., 2005]; speculating that the $P 2_{1} / c$ transition occurs (dotted curve) (this study). See text for details. Seismic X discontinuity observed (shaded region) [Revenaugh and Jordan, 1991; Bagley and Revenaugh, 2008]. Global seismic models: PREM $(230-390 \mathrm{~km}$ in depth, 7.513.0 GPa in pressure, interpolated between reported values) [Dziewonski and Anderson, 1981] and AK135 [Kennett et al., 1995]. Regional seismic models: SNA [Grand and Helmberger, 1984a], TNA [Grand and Helmberger, 1984a], ATL [Grand and Helmberger, 1984b], and PAC06 (interpolated between reported values) [Tan and Helmberger, 2007]. Shear velocity jump required for a seismic reflection with $1.5 \%$ reflection coefficient in a pyrolytic mantle (blue scale at $300 \mathrm{~km}$ ) [Bagley and Revenaugh, 2008]. 
of subducted slabs, will likely require alternative explanations than those considered here. Nevertheless, we find that phase assemblages containing considerable fractions of $\mathrm{Pbca}$-structured iron-bearing enstatite can produce shear velocities that are lower than what is observed under stable tectonic regions (SNA [Grand and Helmberger, 1984a]) and the 1-D Earth model PREM.

[27] In this manuscript, we report the high-pressure elasticity of the ${ }^{57} \mathrm{Fe}$-enriched En 87 sample constrained by X-ray diffraction and nuclear resonant inelastic X-ray scattering experiments up to $19.1 \mathrm{GPa}$. A BM3 EOS fitting gives $K_{T 0}=103 \pm 5 \mathrm{GPa}$ and $K_{T 0}^{\prime}=13 \pm 2$ for the Pbca phase. At $12 \mathrm{GPa}$, a BM3 EOS fitting gives $K_{T 12}=220 \pm$ $10 \mathrm{GPa}$ with $K_{T 12}^{\prime}=8 \pm 4$ for the $P 2{ }_{1} / c$ phase. A structural transition from the $P b c a$ phase to the $P 2_{1} / c$ phase is observed between 10.1 and $12.2 \mathrm{GPa}$, associated with a shear velocity decrease by $\sim 4 \%$. DFT calculations of the partial phonon DOS of enstatite are consistent with $\mathrm{Fe}^{2+}$ dominantly occupying the M2 site, consistent with experimental constraints on the iron occupancy of our sample. By using the shear velocity determined from this study and a finite strain model, we compute shear velocity profiles for different upper mantle petrological compositions. The shear velocity jump associated with the $\mathrm{Pbca}-\mathrm{C} 2 / \mathrm{c}$ transition has a shear reflection coefficient lower than that observed for the seismic "X discontinuity." The low velocities reported in tectonically active regions are unlikely to be explained by the presence of enstatite alone and may require phase assemblages containing hydrous phases and/or partial melt. We find that candidate upper mantle phase assemblages containing $P b c a$-structured enstatite are associated with shear velocity gradients that are higher than the average Earth model PREM but lower than regional studies down to about $250 \mathrm{~km}$ depth.

[28] Acknowledgments. We thank C. A. Murphy, J. K. Wicks, and A. S. Wolf for help in conducting experiments and Y. Fei for synthesizing the sample. We thank the NSF (CAREER EAR-0956166) and the Tectonics Observatory at Caltech (funded through the Gordon and Betty Moore Foundation) for support of this research. Use of the Advanced Photon Source was supported by the U.S. D.O.E., O.S., and O.B.E.S. (DE-AC02-06CH11357) Use of the Advanced Light Source was supported by the U.S. D.O.E., O.S., and O.B.E.S. (DE-AC02-05CH11231). Sector 3 operations, the gasloading system at GSECARS, and beamline 12.2.2 are supported in part by COMPRES under NSF Cooperative Agreement EAR 06-49658.

\section{References}

Akashi, A., Y. Nishihara, E. Takahashi, Y. Nakajima, Y. Tange, and K. Funakoshi (2009), Orthoenstatite/clinoenstatite phase transformation in $\mathrm{MgSiO}_{3}$ at high pressure and high temperature determined by in situ $\mathrm{X}$-ray diffraction: Implications for nature of the X-discontinuity, $J$. Geophys. Res., 114, B04206, doi:10.1029/2008JB005894.

Angel, R. J. (2000), Equations of state, in High-Temperature and HighPressure Crystal Chemistry, Reviews in Mineralogy and Geochemistry, vol. 41, edited by R. M. Hazen and R. T. Downs, pp. 35-59, Mineral. Soc. Am., Washington, D. C.

Angel, R. J., and D. A. Hugh-Jones (1994), Equations of state and thermodynamic properties of enstatite pyroxenes, J. Geophys. Res., 99(B10), 19,777-19,783.

Angel, R. J., and J. M. Jackson (2002), Elasticity and equation of state of orthoenstatite, $\mathrm{MgSiO}_{3}$, Am. Mineral., 87(4), 558-561.

Bagley, B., and J. Revenaugh (2008), Upper mantle seismic shear discontinuities of the Pacific, J. Geophys. Res., 113, B12301, doi:10.1029/2008JB005692.

Baroni, S., P. Giannozzi, and A. Testa (1987), Green's-function approach to linear response in solids, Phys. Rev. Lett., 58(18), 1861-1864.

Baroni, S., S. de Gironcoli, A. Dal Corso, and P. Giannozzi (2001), Phonons and related crystal properties from density-functional perturbation theory, Rev. Modern Phys., 73(2), 515-562.
Bass, J. D., and D. L. Anderson (1984), Composition of the upper mantle: Geophysical tests of two petrological models, Geophys. Res. Lett., 11(3), 237-240.

Boehler, R. (2000), High-pressure experiments and the phase diagram of lower mantle and core materials, Rev. Geophys., 38(2), 221-245.

Caracas, R., and X. Gonze (2010), Lattice dynamics and thermodynamical properties, in Thermodynamic Properties of Solids: Experiment and Modeling, edited by S. L. Chaplot et al., pp. 291-315, Wiley-VCH Verlag, Weinheim.

Chai, M., J. M. Brown, and L. J. Slutsky (1997), The elastic constants of an aluminous orthopyroxene to $12.5 \mathrm{GPa}, J$. Geophys. Res., 102(B7), $14,779-14,785$.

Chu, R., B. Schmandt, and D. V. Helmberger (2011), Juan de Fuca subduction zone from a mixture of tomography and waveform modeling, $J$. Geophys. Res., 117, B03304, doi:10.1029/2012JB009146.

Chu, R., B. Schmandt, and D. V. Helmberger (2012), Upper mantle $\mathrm{P}$ velocity structure beneath the Midwestern United States derived from triplicated waveforms, Geochem. Geophys. Geosy., 13, Q0AK04, doi:10.1029/2011GC003818.

Deuss, A., and J. H. Woodhouse (2002), A systematic search for mantle discontinuities using SS-precursors, Geophys. Res. Lett., 29(8), 1249-1252, doi:10.1029/2002GL014768.

Dewaele, A., F. Datchi, P. Loubeyre, and M. Mezouar (2008), High pressure-high temperature equations of state of neon and diamond, Phys. Rev. B, 77(9), 094106.

Duffy, T. S., and D. L. Anderson (1989), Seismic velocities in mantle minerals and the mineralogy of the upper mantle, J. Geophys. Res., 94(B2), 1895-1912.

Duffy, T. S., and M. T. Vaughan (1988), Elasticity of enstatite and its relationship to crystal-structure, J. Geophys. Res., 93(B1), 383-391.

Dziewonski, A. M., and D. L. Anderson (1981), Preliminary reference Earth model, Phys. Earth. Planet. In., 25, 297-356.

Flesch, L. M., B. S. Li, and R. C. Liebermann (1998), Sound velocities of polycrystalline $\mathrm{MgSiO}_{3}$-orthopyroxene to $10 \mathrm{GPa}$ at room temperature, Am. Mineral., 83(5-6), 444-450.

Frisillo, A. L., and G. R. Barsch (1972), Measurement of single-crystal elastic-constants of bronzite as a function of pressure and temperature, $J$. Geophys. Res., 77(32), 6360-6384.

Frost, D. J. (2008), The upper mantle and transition zone, Elements, 4, $171-176$.

Fuchs, M., and M. Scheffler (1999), Ab initio pseudopotentials for electronic structure calculations of poly-atomic systems using densityfunctional theory, Comput. Phys. Commun., 119(1), 67-98.

Gonze, X., and J. P. Vigneron (1989), Density-functional approach to nonlinear-response coefficients of solids, Phys. Rev. B, 39(18), 13,120-13,128.

Gonze, X., D. C. Allan, and M. P. Teter (1992), Dielectric tensor, effective charges, and phonons in $\alpha$-quartz by variational density-functional perturbation theory, Phys. Rev. Lett., 68(24), 3603-3606.

Gonze, X., G. M. Rignanese, and R. Caracas (2005), First-principles studies of the lattice dynamics of crystals, and related properties, Zeitschrift Kristallogr., 220(5-6), 458-472.

Grand, S. P., and D. V. Helmberger (1984a), Upper mantle shear structure of North America, Geophys. J. Roy. Astr. S., 76, 399-438.

Grand, S. P., and D. V. Helmberger (1984b), Upper mantle shear structure beneath the northwest Atlantic Ocean, J. Geophys. Res., 89(B13), 11,465-11,475.

Hammersley, A. P., S. O. Svensson, M. Hanfland, A. N. Fitch, and D. Hausermann (1996), Two-dimensional detector software: From real detector to idealised image or two-theta scan, High Pressure Res., 14(4-6), 235-248.

Henke, B. L., E. M. Gullikson, and J. C. Davis (1993), X-ray interactions: Photoabsorption, scattering, transmission, and reflection at $\mathrm{e}=50-30,000 \mathrm{eV}, \mathrm{z}=1-92$, Atom. Data Nucl. Data., 54(2), $181-342$.

Hieronymus, C. F., Z. H. Shomali, and L. B. Pedersen (2007), A dynamical model for generating sharp seismic velocity contrasts underneath continents: Application to the Sorgenfrei-Tornquist Zone, Earth. Planet. Sci. Lett., 262, 77-91.

Hohenberg, P., and W. Kohn (1964), Inhomogeneous electron gas, Phys. Rev., 136(3B), B864-B871.

Holland, T. J. B., and S. A. T. Redfern (1997), Unit cell refinement from powder diffraction data: The use of regression diagnostics, Mineral. Mag., 61(1), 65-77.

Hugh-Jones, D. A., and R. J. Angel (1994), A compressional study of $\mathrm{MgSiO}_{3}$ orthoenstatite up to 8.5-GPa, Am. Mineral., 79(5-6), 405-410.

Hugh-Jones, D. A., and R. J. Angel (1997), Effect of $\mathrm{Ca}^{2+}$ and $\mathrm{Fe}^{2+}$ on the equation of state of $\mathrm{MgSiO}_{3}$ orthopyroxene, J. Geophys. Res., 102(B6), $12,333-12,340$ 


\section{ZHANG ET AL.: ELASTICITY AND LATTICE DYNAMICS OF EN87}

Irifune, T., and A. E. Ringwood (1987), Phase transformations in a harzburgite composition to $26 \mathrm{GPa}$ : Implications for dynamical behaviour of the subducting slab, Earth. Planet. Sci. Lett., 86(2-4), 365-376.

Isaak, D. G., I. Ohno, and P. C. Lee (2006), The elastic constants of monoclinic single-crystal chrome-diopside to $1,300 \mathrm{~K}$, Phys. Chem. Miner. 32, 691-699.

Ita, J., and L. Stixrude (1992), Petrology, elasticity, and composition of the mantle transition zone, J. Geophys. Res., 97(B5), 6849-6866.

Jackson, J. M., S. V. Sinogeikin, and J. D. Bass (1999), Elasticity of $\mathrm{MgSiO}_{3}$ orthoenstatite, Am. Mineral., 84(4), 677-680.

Jackson, J. M., S. V. Sinogeikin, M. A. Carpenter, and J. D. Bass (2004), Novel phase transition in orthoenstatite, Am. Mineral., 89, 239-244.

Jackson, J. M., S. V. Sinogeikin, and J. D. Bass (2007), Sound velocities and single-crystal elasticity of orthoenstatite to $1073 \mathrm{~K}$ at ambient pressure, Phys. Earth. Planet. In., 161, 1-12.

Jackson, J. M., E. A. Hamecher, and W. Sturhahn (2009), Nuclear resonant $\mathrm{X}$-ray spectroscopy of $(\mathrm{Mg}, \mathrm{Fe}) \mathrm{SiO}_{3}$ orthoenstatites, Eur. J. Mineral., 21, 551-560.

Jacobsen, S. D., Z. X. Liu, T. B. Ballaran, E. F. Littlefield, L. Ehm, and R. J. Hemley (2010), Effect of $\mathrm{H}_{2} \mathrm{O}$ on upper mantle phase transitions in $\mathrm{MgSiO}_{3}$ : Is the depth of the seismic X-discontinuity an indicator of mantle water content? Phys. Earth. Planet. In., 183, 234-244.

Jahn, S. (2008), High-pressure phase transitions in $\mathrm{MgSiO}_{3}$ orthoenstatite studied by atomistic computer simulation, Am. Mineral., 93, 528-532.

Kennett, B. L. N., E. R. Engdahl, and R. Buland (1995), Constraints on seismic velocities in the Earth from traveltimes, Geophys. J. Int., 122(1), $108-124$.

Kohn, W., and L. J. Sham (1965), Self-consistent equations including exchange and correlation effects, Phys. Rev, 140(4A), A1133-A1138.

Kung, J., B. Li, T. Uchida, Y. Wang, D. Neuville, and R. C. Liebermann (2004), In situ measurements of sound velocities and densities across the orthopyroxene high-pressure clinopyroxene transition in $\mathrm{MgSiO}_{3}$ at high pressure, Phys. Earth. Planet. In., 147, 27-44.

Kung, J., B. Li, T. Uchida, and Y. Wang (2005), In-situ elasticity measurement for the unquenchable high-pressure clinopyroxene phase: Implication for the upper mantle, Geophys. Res. Lett., 32(1), L01307, doi:10.1029/2005GL024904

LeFevre, L. V., and D. V. Helmberger (1989), Upper mantle P velocity structure of the Canadian shield, J. Geophys. Res., 94(B12), $17,749-17,765$.

Liu, W., J. Kung, and B. Li (2005), Elasticity of San Carlos olivine to $8 \mathrm{GPa}$ and $1073 \mathrm{~K}$, Geophys. Res. Lett., 32(16), L16301, doi:10.1029/2005GL023453.

Mao, H. K., J. Xu, and P. M. Bell (1986), Calibration of the ruby pressure gauge to 800-kbar under quasi-hydrostatic conditions, J. Geophys. Res., 91(B5), 4673-4676.

Monkhorst, H. J., and J. D. Pack (1976), Special points for Brillouin-zone integrations, Phys. Rev. B, 13(12), 5188-5192.

Perdew, J. P., K. Burke, and M. Ernzerhof (1996), Generalized gradient approximation made simple, Phys. Rev. Lett., 77, 3865-3868.

Revenaugh, J., and T. H. Jordan (1991), Mantle layering from ScS reverberations. 3. The upper mantle, J. Geophys. Res., 96(B12), 19,781-19,810.

Ringwood, A. E. (1991), Phase transformations and their bearing on the constitution and dynamics of the mantle, Geochim. Cosmochim. Ac., 55(8), 2083-2110.
Rivers, M., V. B. Prakapenka, A. Kubo, C. Pullins, C. M. Holl, and S. D. Jacobsen (2008), The COMPRES/GSECARS gas-loading system for diamond anvil cells at the Advanced Photon Source, High Pressure Res. 28, 273-292.

Schauble, E. A. (2004), Applying stable isotope fractionation theory to new systems, Rev. Mineral. Geochem., 55, 65-111.

Shimizu, H., H. Imaeda, T. Kume, and S. Sasaki (2005), High-pressure elastic properties of liquid and solid neon to $7 \mathrm{GPa}$, Phys. Rev. B, 71, $014,108-014,112$

Shinmei, T., N. Tomioka, K. Fujino, K. Kuroda, and T. Irifune (1999), In situ X-ray diffraction study of enstatite up to $12 \mathrm{GPa}$ and $1473 \mathrm{~K}$ and equations of state, Am. Mineral., 84(10), 1588-1594.

Sturhahn, W. (2000), CONUSS and PHOENIX: Evaluation of nuclear resonant scattering data, Hyperfine Interact., 125(1-4), 149-172.

Sturhahn, W. (2004), Nuclear resonant spectroscopy, J. Phys.-Condens. Mat., 16, S497-S530.

Sturhahn, W., and J. M. Jackson (2007), Geophysical applications of nuclear resonant spectroscopy, in Advances in High-Pressure Mineralogy: Geological Society of America Special Paper 421, edited by E. Ohtani, pp. 157-174, Geological Society of America, Inc., Boulder, Colo., doi:10.1130/2007.2421(09).

Tan, Y., and D. V. Helmberger (2007), Trans-Pacific upper mantle shear velocity structure, J. Geophys. Res., 112, B08301.

Toellner, T. S. (2000), Monochromatization of synchrotron radiation for nuclear resonant scattering experiments, Hyperfine Interact., 125(1-4), $3-28$.

Troullier, N., and J. Martins (1991), Efficient pseudopotentials for planewave calculations, Phys. Rev. B, 43, 1993-2006.

Wang, Y. D. J. Weidner, J. Zhang, G. D. Gwanrnesia, and R. C. Liebermann (1998), Thermal equation of state of garnets along the pyrope-majorite join, Phys. Earth. Planet. In., 105(1-2), 59-71.

Webb, S. L., and I. Jackson (1993), The pressure-dependence of the elastic-moduli of single-crystal ortho-pyroxene $\left(\mathrm{Mg}_{0.8} \mathrm{Fe}_{0.2}\right) \mathrm{SiO}_{3}$, Eur. J. Mineral., 5(6), 1111-1119.

Weidner, D. J., H. Wang, and J. Ito (1978), Elasticity of orthoenstatite, Phys. Earth. Planet. In., 17(2), 7-13.

Woodland, A. B. (1998), The orthorhombic to high-P monoclinic phase transition in $\mathrm{Mg}-\mathrm{Fe}$ pyroxenes: Can it produce a seismic discontinuity? Geophys. Res. Lett., 25(8), 1241-1244.

Woodland, A. B., and R. J. Angel (1997), Reversal of the orthoferrosilitehigh-P clinoferrosilite transition, a phase diagram for $\mathrm{FeSiO}_{3}$ and implications for the mineralogy of the Earth's upper mantle, Eur. J. Mineral., 9(2), 245-254.

Zhang, D., J. M. Jackson, W. Sturhahn, and Y. Xiao (2011), Local structure variations observed in orthoenstatite at high pressures, Am. Mineral., 96 $1585-1592$

Zhang, J. S., P. Dera, and J. D. Bass (2012), A new high-pressure phase transition in natural Fe-bearing orthoenstatite, Am. Mineral., 97(7), 1070-1074

Zhao, J. Y., W. Sturhahn, J. F. Lin, G. Y. Shen, E. E. Alp, and H. K. Mao (2004), Nuclear resonant scattering at high pressure and high temperature, High Pressure Res., 24, 447-457.

Zou, Y., T. Irifune, G. Steeve, M. L. Whitaker, T. Shinmei, H. Ohfuji, R. Negishi, and Y. Higo (2012), Elasticity and sound velocities of polycrystalline $\mathrm{Mg}_{3} \mathrm{Al}_{2}\left(\mathrm{SiO}_{4}\right)_{3}$ garnet up to $20 \mathrm{GPa}$ and $1700 \mathrm{~K}$, J. Applied Phys., 112, 014910, doi:10.1063/1.4736407. 